\title{
Computational approaches to predicting treatment response to obesity using neuroimaging
}

\author{
Leonard Kozarzewski $^{1,2} \cdot$ Lukas Maurer $^{1,2,3} \cdot$ Anja Mähler ${ }^{4,5,6} \cdot$ Joachim Spranger $^{1,2,3,5} \cdot$ Martin Weygandt $^{4,6}$ (D)
}

Accepted: 2 December 2021 / Published online: 23 December 2021

(c) The Author(s) 2021

\begin{abstract}
Obesity is a worldwide disease associated with multiple severe adverse consequences and comorbid conditions. While an increased body weight is the defining feature in obesity, etiologies, clinical phenotypes and treatment responses vary between patients. These variations can be observed within individual treatment options which comprise lifestyle interventions, pharmacological treatment, and bariatric surgery. Bariatric surgery can be regarded as the most effective treatment method. However, long-term weight regain is comparably frequent even for this treatment and its application is not without risk. A prognostic tool that would help predict the effectivity of the individual treatment methods in the long term would be essential in a personalized medicine approach. In line with this objective, an increasing number of studies have combined neuroimaging and computational modeling to predict treatment outcome in obesity. In our review, we begin by outlining the central nervous mechanisms measured with neuroimaging in these studies. The mechanisms are primarily related to reward-processing and include "incentive salience" and psychobehavioral control. We then present the diverse neuroimaging methods and computational prediction techniques applied. The studies included in this review provide consistent support for the importance of incentive salience and psychobehavioral control for treatment outcome in obesity. Nevertheless, further studies comprising larger sample sizes and rigorous validation processes are necessary to answer the question of whether or not the approach is sufficiently accurate for clinical real-world application.
\end{abstract}

Keywords Personalized medicine $\cdot$ Obesity treatment $\cdot$ Machine learning $\cdot$ Task-fMRI $\cdot$ Resting-state fMRI $\cdot$ Biomarkers

$\begin{array}{llll}\text { Abbreviations } & \text { DA } & \text { Dopamine } \\ \text { ALFF } & \text { Amplitude of low frequency fluctuations } & \text { DD } & \text { Delay discounting } \\ \text { BMI } & \text { Body mass index } & \text { dlPFC } & \text { Dorsolateral prefrontal cortex } \\ \text { BS } & \text { Bariatric surgery } & \text { DTI } & \text { Diffusion tensor imaging } \\ \text { CR } & \text { Cue reactivity } & \text { FC } & \text { Functional connectivity } \\ \text { CrvR } & \text { Craving regulation } & \text { FCD } & \text { Functional connectivity density } \\ \text { CSF } & \text { Cerebrospinal fluid } & \text { fMRI } & \text { Functional magnetic resonance imaging } \\ \text { D2R } & \text { Dopamine receptor subtype D2 } & \text { GM } & \text { Grey matter }\end{array}$

Martin Weygandt

martin.weygandt@charite.de

1 Charité - Universitätsmedizin Berlin, corporate member of Freie Universität Berlin and Humboldt-Universität zu Berlin, Clinic of Endocrinology, Diabetes and Metabolism, 10117 Berlin, Germany

2 Charité - Universitätsmedizin Berlin, corporate member of Freie Universität Berlin and Humboldt-Universität zu Berlin, Charité Center for Cardiovascular Research, 10117 Berlin, Germany

3 Berlin Institute of Health at Charité - Universitätsmedizin Berlin, 10117 Berlin, Germany
4 Max Delbrück Center for Molecular Medicine and Charité - Universitätsmedizin Berlin, corporate member of Freie Universität Berlin and Humboldt-Universität zu Berlin, Experimental and Clinical Research Center (ECRC), 13125 Berlin, Germany

5 DZHK (German Center for Cardiovascular Research), partner site Berlin, Berlin, Germany

6 Charité - Universitätsmedizin Berlin, corporate member of Freie Universität Berlin and Humboldt-Universität zu Berlin, NeuroCure Clinical Research Center, 10117 Berlin, Germany 


$\begin{array}{ll}\text { IC } & \text { Independent component } \\ \text { LAGB } & \text { Laparoscopic adjustable gastric banding } \\ \text { LI } & \text { Lifestyle intervention } \\ \text { LMM } & \text { Linear mixed model } \\ \text { LOO-CV } & \text { Leave-one-out cross validation } \\ \text { MRI } & \text { Magnetic resonance imaging } \\ \text { OLS } & \text { Ordinary least squares } \\ \text { PE } & \text { Physical exercise } \\ \text { PET } & \text { Positron-Emission-Tomography } \\ \text { PI } & \text { Pharmacological intervention } \\ \text { RS } & \text { Resting-state } \\ \text { RYGB } & \text { Roux-en-Y gastric bypass } \\ \text { SG } & \text { Sleeve gastrectomy } \\ \text { SMRI } & \text { Structural magnetic resonance imaging } \\ \text { SVC } & \text { Support vector classification } \\ \text { VBM } & \text { Voxel-based morphometry } \\ \text { vmPFC } & \text { Ventromedial prefrontal cortex } \\ \text { WM } & \text { White matter }\end{array}$

\section{Introduction}

The global obesity epidemic is one of today's major public health concerns. According to the World Health Organization, 650 million adults or $13 \%$ of the world's adult population were obese in 2016 and the worldwide prevalence in adults nearly tripled between 1975 and 2016. In addition to these concerning epidemiological characteristics, obesity is associated with multiple adverse consequences, including increased risk for cardiovascular disease, diabetes, cancer, premature mortality as well as depression and anxiety [1-7]. Besides social [8], genetic [9], hormonal [10] and behavioral [11-13] factors, central nervous factors promote the development and maintenance of obesity. Neural mechanisms that (i) underlie impaired food reward [14, 15], (ii) link food cues to (anticipated) reward $[16,17]$ and (iii) underlie reduced psychobehavioral control $[16,18,19]$ are considered the main central nervous contributors to obesity. In developed countries these effects are increased by 24 -h advertisement and availability of low cost, calorie dense, and highly palatable food.

Compatible with this multi-factorial etiology, three groups of treatments exist: lifestyle interventions (LIs), bariatric surgery (BS) and pharmacological interventions (PIs). LIs include caloric restriction, physical exercise, eating behavior modification and dietary counselling. Balanced hypocaloric diets induce clinically meaningful weight loss [20]. Optimal weight loss and maintenance are achieved when caloric restriction and physical exercise are combined $[21,22]$. However, long-term weight regain is relatively common [23].

BS is currently the most effective treatment with regard to weight loss, attenuation of comorbidity (e.g., type 2 diabetes) and mortality prevention [24, 25] and thus the treatment of choice for severe obesity [26]. Sleeve gastrectomy (stomach volume reduction to 80 to $120 \mathrm{~mL}$ ) is the most frequently recommended BS technique. Nevertheless, there is considerable variability in weight loss. Weight regain occurs in $20-30 \%$ of patients [27-34]. Long-term weight regain has been associated with a reversal of surgery-induced hormonal variations (e.g., in ghrelin and GLP-1; [35]), post-bariatric hypoglycemia [36], dietary non-adherence [37], and physical inactivity [38]. Problematic behavioral patterns are likely further aggravated in psychiatric patients [39]. The safety of BS has improved drastically in the last two decades, with perioperative mortality rates ranging from 0.03 to $0.2 \%$ [40-43]. However, complications can still occur and include early complications such as bleeding, thromboembolism, bowel obstruction and wound infection and as well as late complications such as stricture, reflux disease, cholelithiasis, hernia, nutritional and vitamin deficiencies, and dumping syndrome [44, 45]. In the long term up to $22 \%$ of patients require reoperation [46-49]. Due to the differences in efficiency and risk between treatment options, a prognostic tool which predicts treatment success and could thus guide individual treatment choices in a personalized medicine framework is highly desirable.

Only few drugs are used in clinical obesity management, including Orlistat, a pancreatic lipase inhibitor, Phentermine/topiramate, a sympathomimetic, appetite suppressant, Lorcaserin, a 5-HT2C receptor activator, Naltrexone/ bupropion, a transmitter reuptake inhibitor and Liraglutide, a glucagon-like peptide 1 (GLP-1) analogue. Especially GLP1-analoge trials have produced promising results with Liraglutide treatment usually resulting in a weight loss of 4 to $6 \mathrm{~kg}$ and Semaglutide treatment demonstrating even greater weight loss $[50,51]$. Side effects of liraglutide include gastrointestinal symptoms, such as nausea, diarrhea, constipation, and vomiting [52]. PI weight loss is partly or completely reversed after treatment [53]. PIs are only recommended as add-on to LIs [54]. See [54] for a more detailed overview on LI, [55] for BS, and [52] for PI.

Currently, a variety of studies exist that use computational approaches and neuroimaging signals to predict treatment outcome in obesity. In this review, we explain the key central nervous mechanisms assessed in these studies, present the different neuroimaging and computational prediction techniques, and give a detailed overview of existing studies. In the Discussion, we pay special attention to the questions of (i) whether the results obtained are sufficient to legitimate clinical real-world applications (which is presumably not yet the case), (ii) what could be done to meet this requirement and (iii) how statistical analyses could be improved to provide more detailed models for "treatment" and "treatment outcome". 
We included longitudinal LI, BS, and PI studies. We required a period of at least one months between treatment initiation and the latest follow-up. Compatible with the general meaning of "prediction" as a forecast of future events and of "prediction" as a statistical process modelling some factor based on other factors, we included studies that prognose future treatment outcome using neuroimaging biomarkers and studies that predict treatment-induced variations in outcome markers based on variations in neuroimaging parameters across treatment.

\section{Central nervous mechanisms affecting body weight}

At least partially motivated by the discovery of overlapping psychobehavioral symptoms in persons with obesity and substance dependence such as loss of control over consumption and craving $[16,56]$, neuroimaging research on central nervous parameters impacting body weight has focused on three major reward-related mechanisms: Reward system hyposensitivity to food consumption, reward system hyperresponsivity to stimuli predicting food consumption, and dysfunctional psychobehavioral or goal-directed control system respectively.

\subsection{Reward system hyposensitivity to food consumption}

A reduced sensitivity of the brain reward system to food consumption (including the actual pleasurable impact of consumption) is regarded as a factor that triggers excessive overeating as a method of compensation [14, 15, 57]. In accordance with addiction research, a reduced striatal dopamine (DA) release after food consumption and reduced availability of DA receptor subtype D2 (D2R) are discussed as causes for said hyposensitivity.

Specifically, Small et al. found a food-intake induced DA release after a $16 \mathrm{~h}$ fast that reflected the pleasantness of food consumption in normal weight persons [58]. This is compatible with findings showing that amphetamineinduced DA release correlates with the experienced pleasantness of amphetamine consumption in healthy subjects [59] and a reduced DA release in detoxified cocaine abusers [60]. The pleasurable impact of consumption is frequently referred to as "liking" [17]. Van de Giessen et al. found reduced DA release in obese persons in the sense that amphetamine induced a significant DA release in lean but not obese persons [57]. Based on these findings, it was concluded that blunted DA release after consumption is a mechanism underlying compensatory overeating in obesity (e.g., [57]). Moreover, in agreement with findings made for addiction [61], obesity research found that the availability of striatal D2R is significantly decreased in obese persons $[15,62]$ and is negatively related to their BMI [15]. Consistently, Johnson \& Kenny found a progressive decrease in D2R-availability accompanied by a progressive increase in compulsion-like overeating in rats randomized into an overeating condition compared to control animals [14] and Geiger et al. found reduced extracellular dopamine in the striatum in a comparable experimental setting [63]. Johnson $\&$ Kenny concluded that the observed progressive dopaminergic hyposensitivity reflects the transition from normal to compulsive overconsumption [14].

However, some findings question the importance of (dopaminergic) reward system hyposensitivity as a risk factor for weight gain. Hardman et al. found that suppressing DA signals leads to a reduced food intake in humans [64]. Tellez and colleagues showed that down-regulation of DA release due to a prolonged high-fat diet reduces caloric intake in rodents [65]. Several studies on addiction research depleting/antagonizing DA functioning did not find an impact on drug or food-liking. Only a reduction in motivational properties (i.e., of "drug-wanting", see Sect. 2.2) was found [66, 67]. Importantly, Tellez and colleagues also showed that application of oleoylethanolamine restores DA release [65]. Oleoylethanolamine is a lipid messenger whose synthesis is suppressed due to the high-fat diet. Their study provides a mechanism that explains reduced DA release as a consequence of a prolonged high-fat diet. Consistent with this description of reduced DA release as a consequence (and not a cause) of an excessive calorie intake and given the experimental design applied by Johnson \& Kenny [14], one might assume that the progressive decrease in D2R-availability observed in their study reflects the end-point of rather than the transition to compulsive overconsumption. See [68-70] for an overview. Finally, the exact role of calorie-intake related DA receptor alterations appears unclear due to findings of Dobbs et al. showing that D2R downregulation can be associated with a D1R hyper-reactivity, suggesting more heterogeneous DA adaptations [71].

Therefore, a causative role of a DA-mediated reward system hyposensitivity for weight gain remains debatable. Only one of the two Positron-Emission-Tomography (PET) studies directly evaluating a link between DA functioning and future weight loss $[72,73]$ found such a link [72]. Authors elaborating on alternative neurotransmitters suggest endorphins or endocannabinoids as substrates of drug or food liking (see e.g., [17] for an overview). An important role of endorphins would be consistent with findings of the PET study not showing a link for DA [73] but showing negative associations between body weight variations and $\mu$-opioid receptor availability in amygdala, insula, ventral striatum, and putamen. In conclusion, additional research on DAbased reward hyposensitivity appears necessary given contradictory findings. 


\subsection{Reward system hyperresponsivity to stimuli predicting food consumption}

"Incentive salience" is a motivational mechanism considered to initiate compulsive food seeking and consumption after food cue exposure because these cues were coupled to reward (consumption) by Pavlovian conditioning in the learning history of an individual. Consequently, food cues are predictive of food intake and can acquire similar motivational properties as food reward after repeated couplings [74]. Incentive salience relies on a hypersensitivity of the DA reward system to these cues [17] and corresponds to a strong desire, a strong "I want to consume feeling" on a psychological level. This desire has consistently been termed as "wanting" [17] or "craving" [56].

Early work relating this cue-dependent motivational mechanism to striatal DA was done by Schultz et al. who showed in a pivotal animal study that the response of striatal DA neurons varies across different stages of food exposure. Animals respond to palatable food consumption during early stages of exposure, but only to cues predicting consumption after repeated exposure [75]. Hamid et al. linked striatal DA to cue-sensitivity by showing that it reflects the willingness to engage in effortful activities to obtain reward after cue exposure in rats [76]. Furthermore, the role of striatal DA for food wanting in humans was underlined by van de Giessen et al. who found that DA release after amphetamine intake in obese persons correlated with food craving on trait level [57].

Although incentive salience is primarily a motivational phenomenon, it also comprises attentional, affective, learningrelated, and behavioral facets. Consistently, functional magnetic resonance imaging (fMRI) studies using cue reactivity (CR) tasks did not only find striatal hyperresponsivity to high-calorie food cues but also a hyperresponsivity in anterior cingulate cortex and visual areas, amygdala, orbitofrontal cortex, and hippocampus [77-80]. CR tasks represent the key functional paradigms for studying incentive salience which contrast neural signals emerging during perception of food cues to those during control conditions (see 3.1.1). In this framework, the anterior cingulate cortex / amygdala / visual areas are supposed to modulate the attentional [81] / emotional [82] / sensory salience of food cues (cf. [83]). The orbitofrontal cortex might underlie stimulus - outcome encoding in Pavlovian conditioning [84]. The hippocampus plays an inhibitory role in appetitive Pavlovian conditioning [82]. Consistent with the concept of incentive salience, a hyperresponsivity in these areas was found to predict unfavorable treatment outcome in a variety of reviewed CR studies.

However, some studies did not support a link between incentive salience and treatment outcome. Specifically, neither the BS fMRI study of Bach et al. nor the PI fMRI study of Ten Kulve et al. found significant associations between brain activity evoked by food-cue presentation before the treatment and treatment-induced weight loss $[85,86]$.

\subsection{Dysfunctional goal-directed control system}

A dysfunctional psychobehavioral or goal-directed control system and reduced modulation of incentive salience by this system is considered a further mechanism contributing to overeating [19]. This can be understood when viewing eating behavior from a decision-making perspective. The Pavlovian incentive salience mechanism primarily mediated by the striatal DA system can be seen as a decision-making mechanism favoring choices that have previously been associated with immediate and highly rewarding consequences. In line with its subcortical location, this striatal mechanism does not consider future consequences [19]. By contrast, the goal-directed decision-making system is driving (food) choices by comparing different options based on action plans encoding their present and future consequences [19, 87]. Thus, this system could inhibit the impulse to eat a tasty but unhealthy food (e.g., triggered by the striatal DA system) because it predicts that the negative consequences of future overweight outweigh (i.e., have a higher negative value) the positive consequences of immediate reward (i.e., their positive value) [19].

Hare et al. identified value-based goal-directed decisionmaking regions in the brain by having self-reported dieters choose between two food items: a constant reference item with average taste- and health related properties and another that varied in these aspects [88]. Ventromedial prefrontal cortex (vmPFC) activity predicted the food choice (i.e., its value) independent of the food's tastiness or healthiness. Activity in the dorsolateral prefrontal cortex (dlPFC) reflected self-control (i.e., was higher when subjects chose healthy). VmPFC and dlPFC activity correlated only during successful self-control trials. The authors concluded that the vmPFC computes a value-signal which determines foodchoice and relies on both factors, reward (taste) and control (health) only when it reflects control-related dlPFC activity. VmPFC activity alone only reflects reward (taste).

Another study employed a delay discounting (DD) paradigm [87]. In DD tasks, participants have to decide repeatedly between rapidly available smaller rewards or larger rewards available at a later time (see 3.1.2). A weaker preference for earlier smaller than for larger delayed rewards is considered as a behavioral marker for goal-directed control. This study highlighted the importance of the interplay between fronto-parietal control areas and striatal incentive salience areas for goal-directed control. Stronger goaldirected control depends on stronger lateral-prefrontal relative to striatal activity. Please see [89] for findings suggesting an inhibitory impact of prefrontal on incentive salience 
regions including striatal ones (modulated by the specific calorie-restriction type applied). A direct link between key regions of goal-directed and striatal Pavlovian control is consistent with the finding that DA depleted mice do not at all initiate goal-directed behaviors including feeding [90]. In addition, animal studies suggest that the insular cortex also contributes to goal-directed decision-making as lesions to this area impaired the ability of rats to devalue food after satiety and to adjust their food choice accordingly [91].

The clinical importance of this factor has been demonstrated on a behavioral level in DD studies showing reduced goal-directed control in obese persons $[92,93]$. These studies controlled for nuisance factors (e.g., age and income). Studies not controlling for these variables failed to show these effects (e.g., $[94,95])$. Neuroimaging studies in obese subjects revealed a link between reduced D2R availability in the striatum and a reduced resting-state (RS) glucose metabolism in regions involved in goal-directed decisionmaking such as vmPFC and dlPFC [96]. In [97] we could demonstrate the importance of behavioral and neural measures of goal-directed control and their interplay with striatal Pavlovian regions for the dietary success of obese persons in a 12-week LI. Higher behavioral goal-directed control was coupled to better weight loss. Functional connectivity (FC) between vmPFC and dIPFC was positively related to behavioral control and weight loss and FC between vmPFC and dorsal striatum was negatively linked with future weight loss. We evaluated the role of the interplay between Pavlovian and goal-directed neural systems in a LI study by testing whether future dietary weight loss and long-term maintenance after treatment across 39 months could be predicted based on activity assessed in a food CR paradigm, a foodspecific DD paradigm, and the interaction of these activities [18]. This revealed a strong link between future long-term weight loss and interactions between visual Pavlovian and insular control areas.

\section{Neuroimaging techniques and parameters used for prediction}

Task- and RS-fMRI as well as structural MRI (sMRI) are the neuroimaging acquisition techniques predominantly employed in the reviewed studies. fMRI provides indirect markers of neural activity by measuring vascular responses to heightened metabolic demands of active neurons [98] while sMRI provides information on various brain tissue characteristics. Neuroimaging parameters derived for prediction from fMRI and sMRI can be subdivided in two major groups: Parameters characterizing specific, localized processing of individual brain regions ("functional segregation") and those reflecting the interplay or FC of activity among different regions respectively ("functional integration"). All methods described in this section are illustrated in Fig. 1.

\subsection{Task-fMRI}

Three task-based fMRI paradigms outlined below are currently used for treatment outcome prediction in obesity: CR, DD, and food craving regulation (CrvR). [97, 99-101] used them to derive measures of $\mathrm{FC}$, the rest exclusively computed markers of localized activity in individual brain coordinates (i.e., voxels).

In these task-fMRI studies, markers of localized activity (referred to as "Voxel CR, DD, or CrvR activity" in the following), are computed in a two-step process. First, three-dimensional maps of neural activity reflecting the targeted mechanism in individual voxels are determined for each participant and time point. Second, these parameters are entered into a predictive group-level analysis utilizing methods described in Sect. 4.

Task-related FC markers are also computed in a two-step procedure ("Seed-to-voxel CR FC" or "Seed-to-voxel DD FC") in the majority of studies evaluating task-related FC $[97,99,100]$. First, a seed coordinate sensitive to the evaluated factor is selected based on prior knowledge and the association between its time series (potentially modulated by the time course of a condition of interest [99, 100]; see [102]) and all other voxels is computed. Second, the voxelwise correlation/regression coefficients are entered into a group-level analysis.

\subsubsection{Cue reactivity}

The key experimental design to study incentive salience, which is applied in the majority of all reviewed studies (see Tables 1 - 3), is the food CR paradigm. Reflecting the notion that exposure to food-cues (e.g., pictures, taste, odor, or imagined food items) can trigger food-wanting/craving and subsequently food-intake [74], CR tasks typically present pictures of high-calorie food and control items such as pictures of neutral objects or low-calorie foods. Participantspecific voxel contrast maps reflecting activity related to incentive salience are then computed by subtracting activity during the control condition from activity during presentation of palatable foods to control for non-food related activation.

\subsubsection{Delay discounting}

DD tasks are well established experimental designs for the study of goal-directed control in obesity (e.g., [18, 97, 103-106]) in which participants have to decide multiple times between immediately available smaller rewards and larger delayed ones. Several methods exist for computing 
a
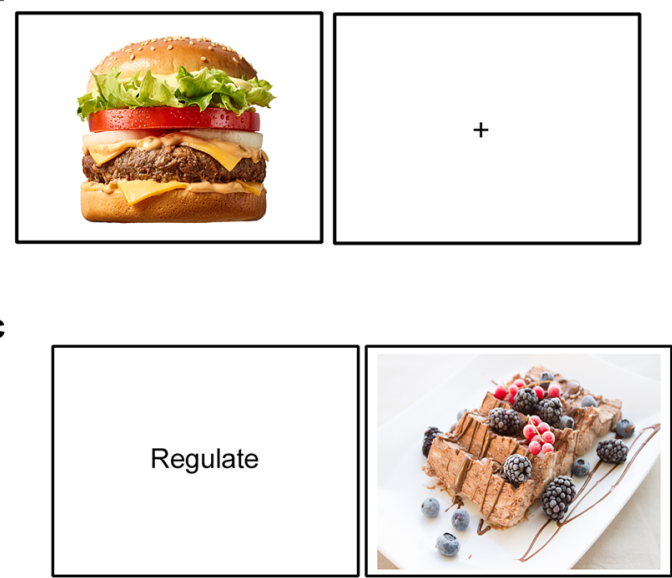

b
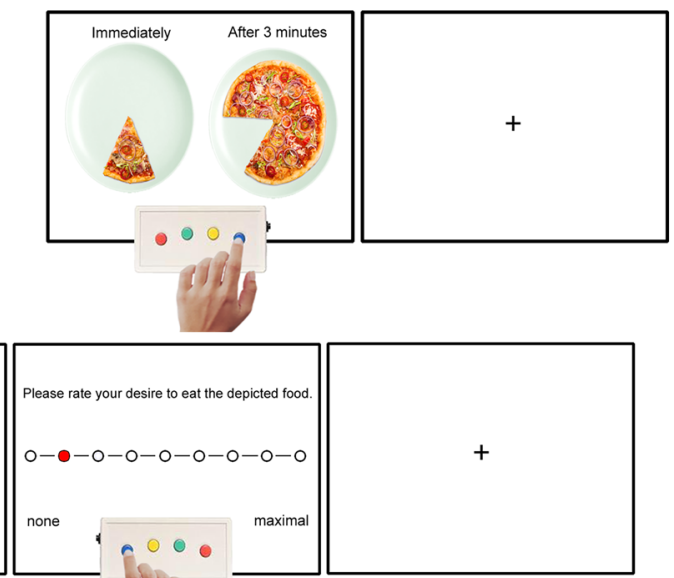

1.15

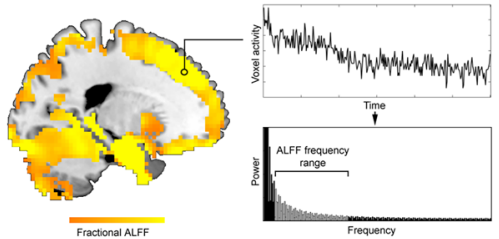

e

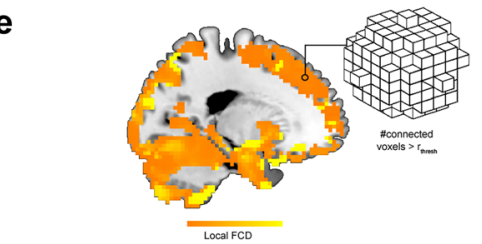

f

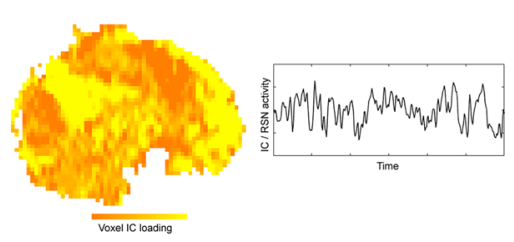

g
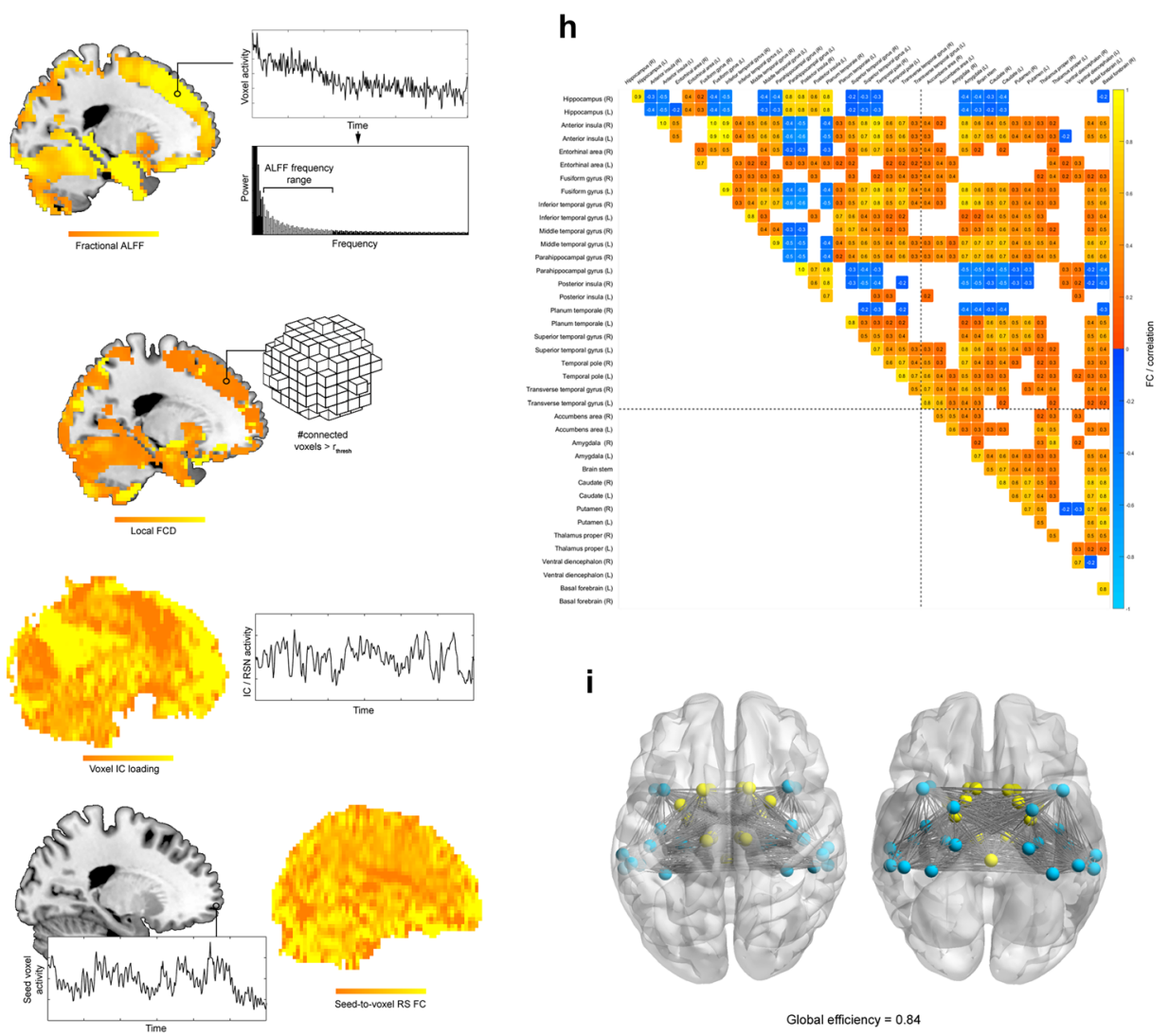

i

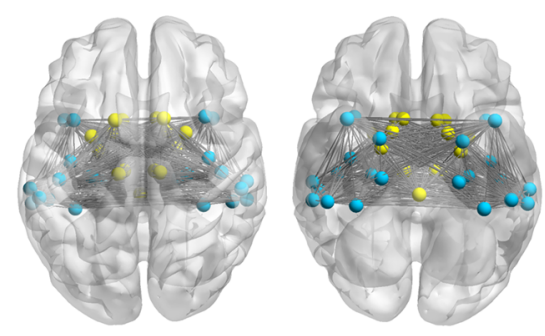

Global efficiency $=0.84$
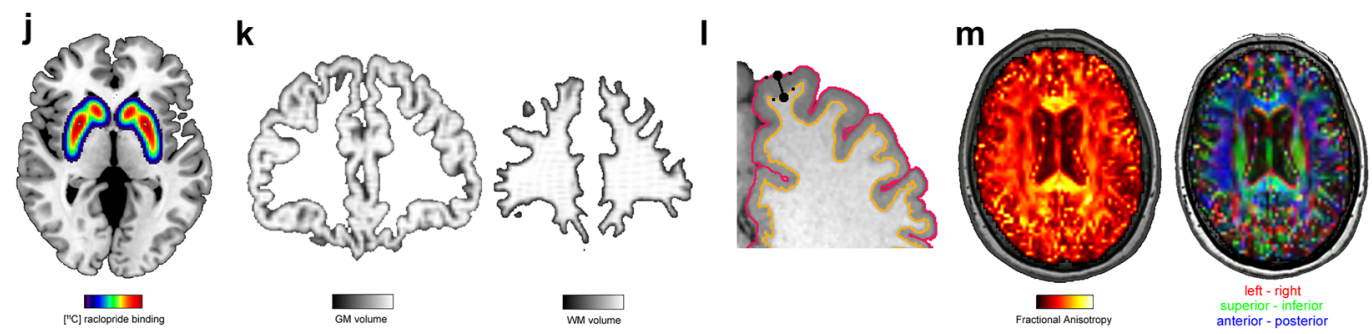
4Fig. 1 Neuroimaging techniques and parameters utilized in the reviewed studies. (a)-(c) illustrate the basic layouts of the three fMRI tasks, i.e., CR (a), DD (b), and food CrvR (c). The panels (d)-(i) depict the different parameters derived from RS fMRI. In particular, 1d illustrates the ALFF method, (e) FCD mapping. (f) shows a component loading map for a RS-network extracted by independent component analysis. Moreover, (g) illustrates the seed-to-voxel FC approach. (h) shows a correlation (i.e., FC) matrix obtained for temporal and deep GM regions for RS fMRI data of a single subject and time point. FC depicted is thresholded at $r=|0.5|$. (Only) temporal and deep GM regions were selected to facilitate a better readability of the panel. The network depicted in (i) corresponds to the areas / FC depicted in the correlation matrix in (h). This network has a global efficiency of 0.84 . (j) illustrates a PET scan using the $\left[{ }^{11} \mathrm{C}\right]$ raclopride radio-tracer. Finally, (k)-(m) depict the structural MRI measures. Specifically, (k) shows a brain voxel map of the GM (left) and WM (right) volume of a participant determined with VBM. (l) illustrates an approach to cortical thickness estimation that treats the distance between two closest vertices on the opposing WM/GM surface and the GM/pial surface as measure of cortical thickness for the corresponding cortex segment. (m) illustrates the fractional anisotropy determined with DTI for a single participant and time point on the left. In order to illustrate the directional information contained in DTI maps (and used for fiber tractography), the direction of the first tensor for a given voxel is depicted with a red-green-blue coding on the right. For further details, see text

participant-specific voxel contrast maps reflecting goaldirected control in DD tasks such as contrasting more immediate options to more delayed ones [87], or contrasting difficult (similar attractiveness of immediate and delayed choices) vs. easy trials (dissimilar attractiveness; e.g., [106]). Another method is to first determine a behavioral measure of goal-directed control that allows modelling the subjectspecific value of options (rewards) based on their reward magnitude and delay and to then compute the voxel-wise association between this model function and local activity (e.g., $[97,107])$.

\subsubsection{Food craving regulation}

Paradigms requiring their participants to actively regulate affective states induced by generic emotional stimuli have either been applied without changes in obesity research or were slightly varied to study craving regulation induced by food stimuli. For example, a study investigating emotion regulation during presentation of generic affective stimuli found that obese persons have more emotion regulation difficulties assessed via questionnaires than controls. In addition, higher vmPFC activity during regulation is associated with less regulation difficulties [108]. Food CrvR paradigms (used for treatment outcome prediction in [68]) evaluate the effect of regulation strategies on food-cue elicited craving. Trials typically start by presenting a strategy word (e.g., "permit" or "regulate" [69]), which is followed by a highor low-calorie food picture that should either be perceived in a permissive fashion (i.e., allowing oneself to perceive the potentially induced craving) or during application of a regulation strategy. Finally, participants rate their desire to consume the depicted food. Contrasting signals emerging during high-calorie food \& permit (high-calorie food \& regulate) vs. low-calorie food \& permit (high-calorie food $\&$ permit) enables computing voxel activity maps for incentive salience (goal-directed control). Thus, this paradigm might be seen as a mixture of an incentive salience and goaldirected control task.

\subsection{Resting-state fMRI}

RS fMRI measures spontaneous low-frequency brain activity under task-free conditions and has revealed fundamental aspects of how the brain is organized and works, i.e., its intrinsic organization in separate networks (i.e., the RS networks [109]) or that RS network activity impacts taskrelated activity of RS network [110].

\subsubsection{Amplitude of low frequency fluctuations}

The Amplitude of low frequency fluctuations (ALFF) method is applied in three reviewed BS studies [111-113] and characterizes spontaneous low-frequency brain activity by estimating the magnitude of these fluctuations in a small frequency band (e.g., from 0.01 to 0.08 Hertz [114]) for each voxel coordinate. Initially, the average square root of the power in this frequency band of a given voxel's time series divided (i.e., standardized) by the average of this parameter across all voxels was used as voxel ALFF measure [115]. The improved fractional ALFF method uses the square root averaged across the full power spectrum for a given voxel as a standardization method [116]. It was suggested that frequency sub-bands within 0.01 to 0.08 Hertz reflect spontaneous low-frequency activity of different neural tissue types and that several diseases other than obesity induce alterations in ALFF (see [117] for an overview).

\subsubsection{Functional connectivity density mapping}

Functional connectivity density (FCD) mapping (employed in one reviewed study [118]), estimates the degree of FC for each voxel, and primarily aims to reveal areas of dense local FC (so-called "hubs"; [119]). Specifically, "local FCD" reflects the number of voxels in a cluster surrounding a center voxel having at least a predefined FC. "Global FCD" corresponds to the number of voxels having a suprathreshold FC with the center voxel irrespective of neighborhood minus its local FCD. The clinical relevance of FCD was e.g. supported by findings of an altered local FCD in schizophrenia [120] and a relation of FCD and severity of subclinical depressive symptoms in healthy elderly [121]. 


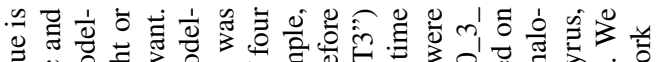

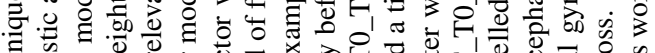

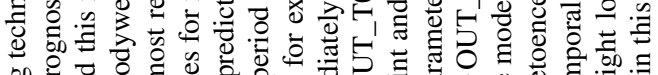
on

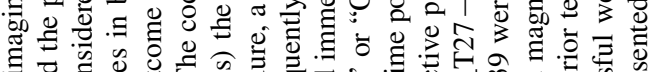

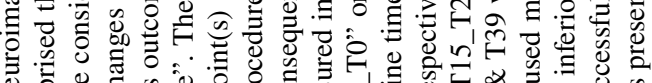

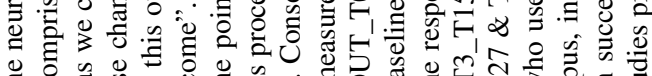

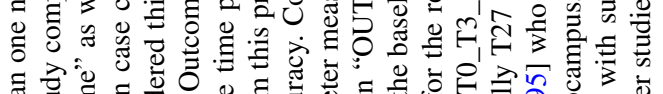

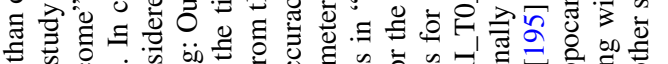

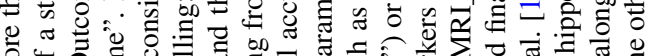

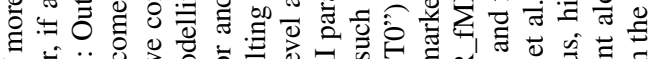

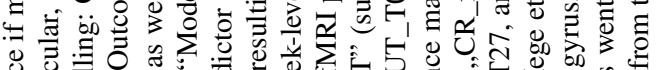

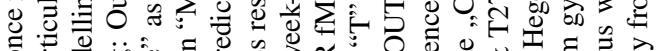
o

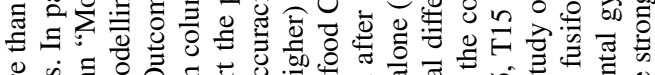

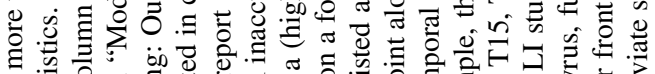

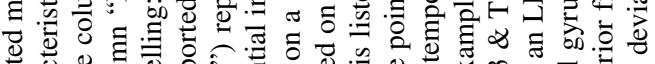

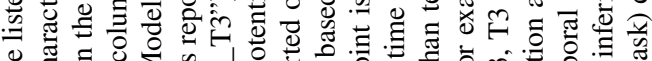

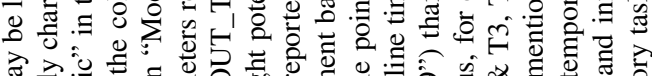

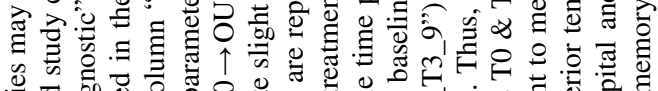

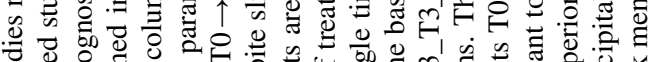

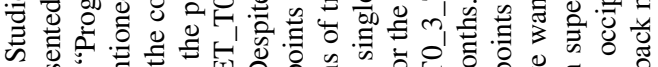

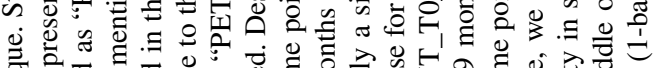

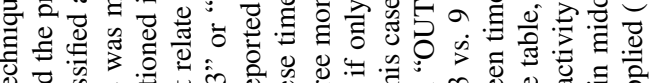

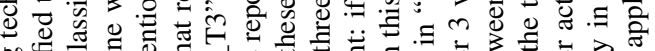

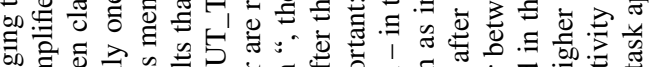

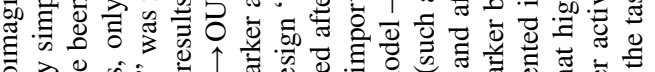

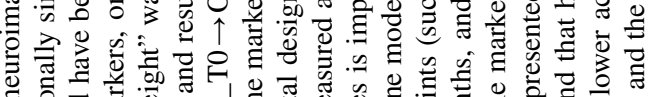

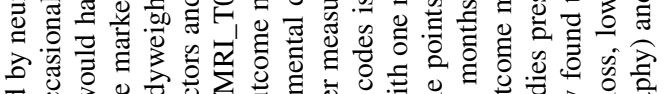

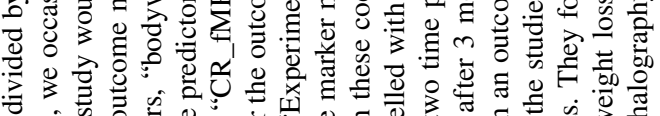

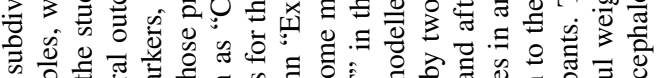

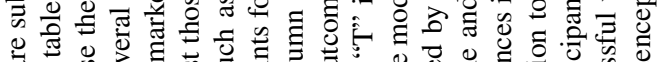

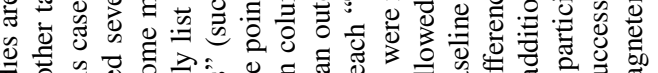

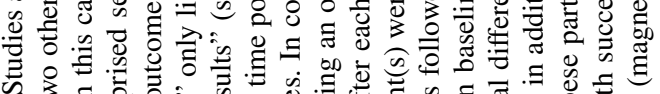

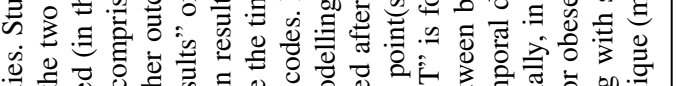

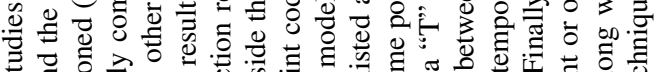

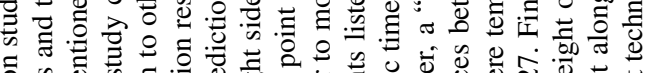
है.

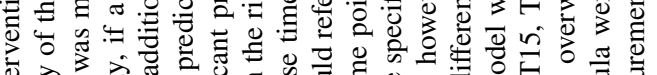

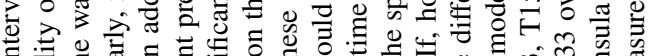

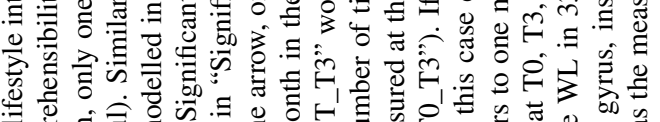

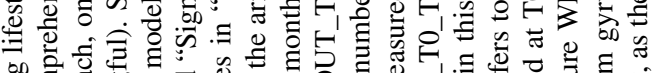

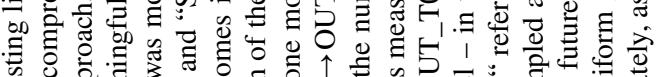

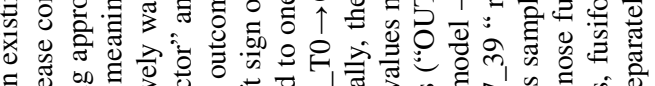
₹

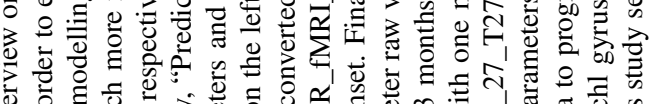

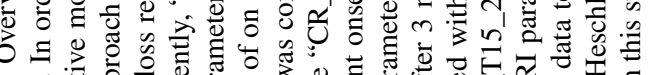

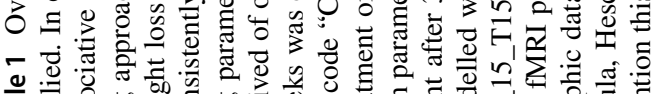

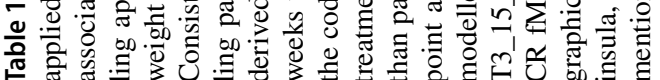

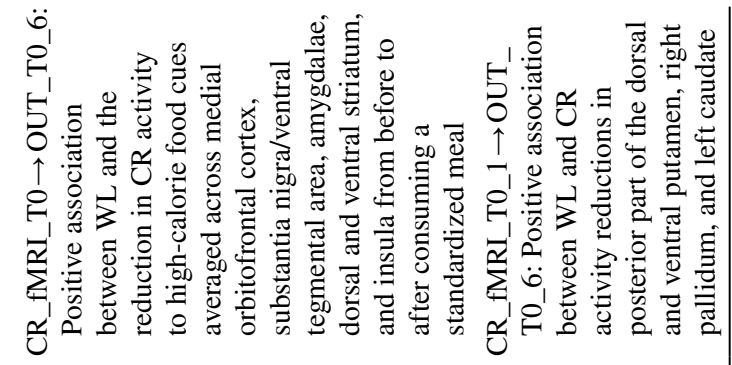

3

高

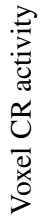

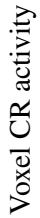

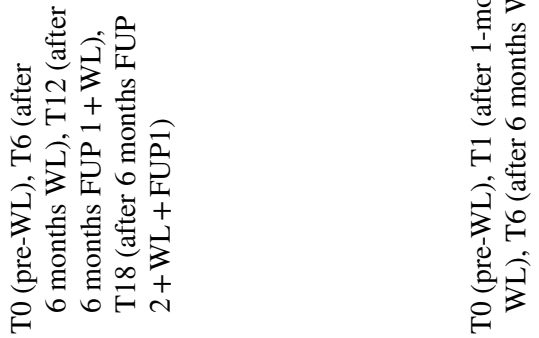

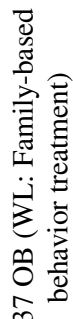

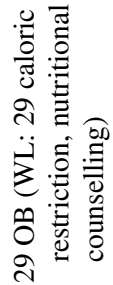

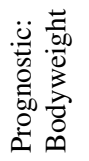

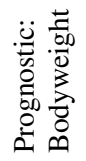

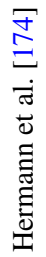




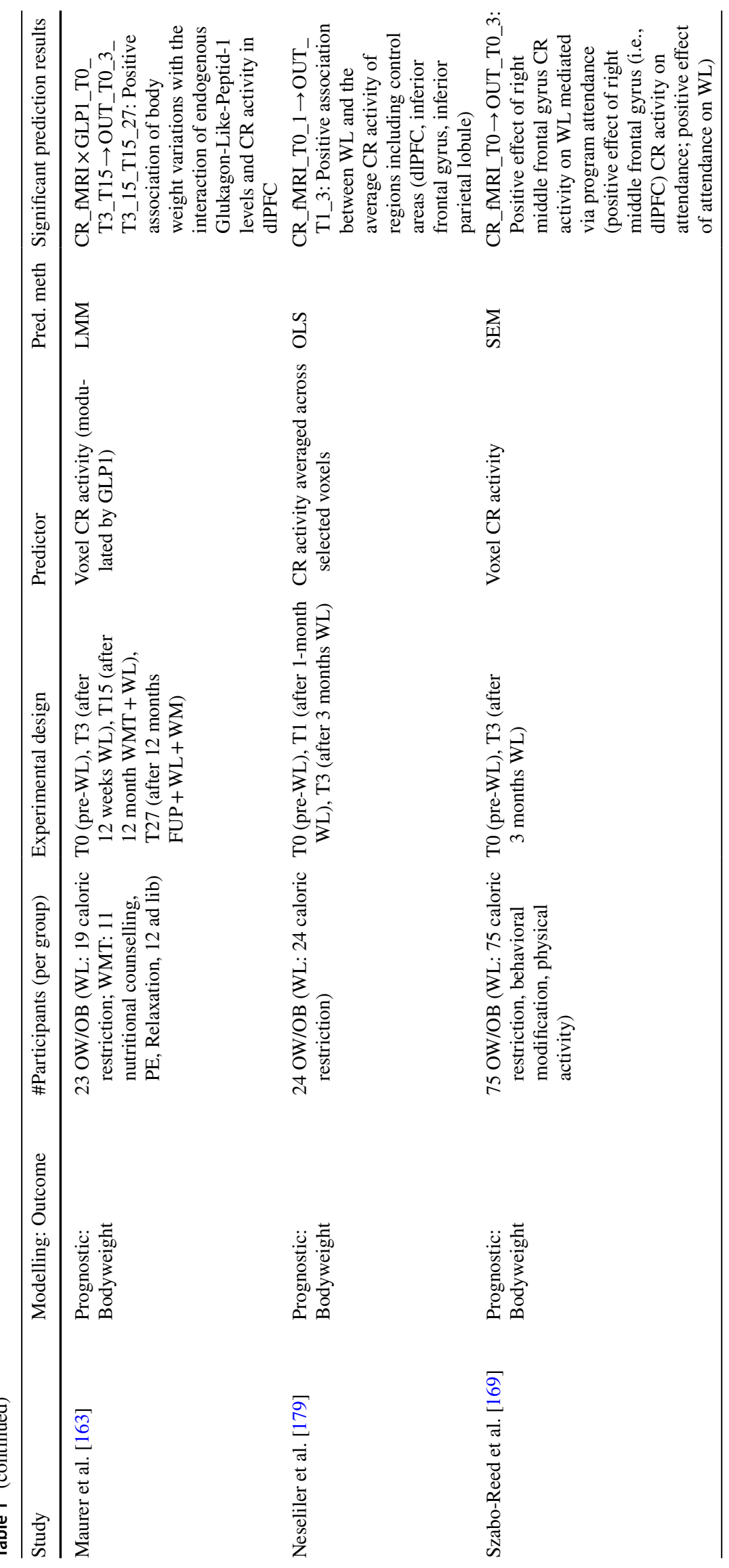




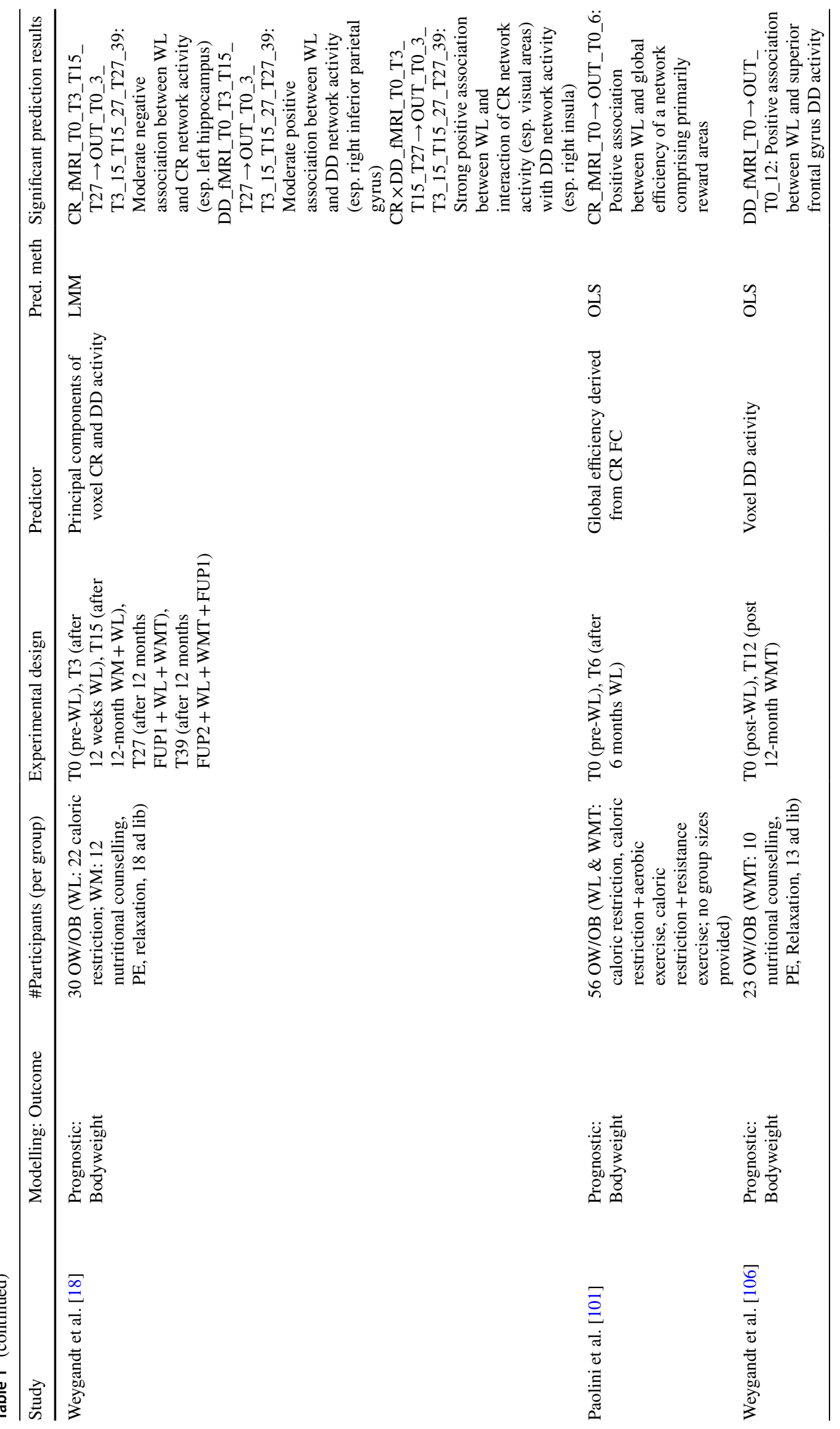




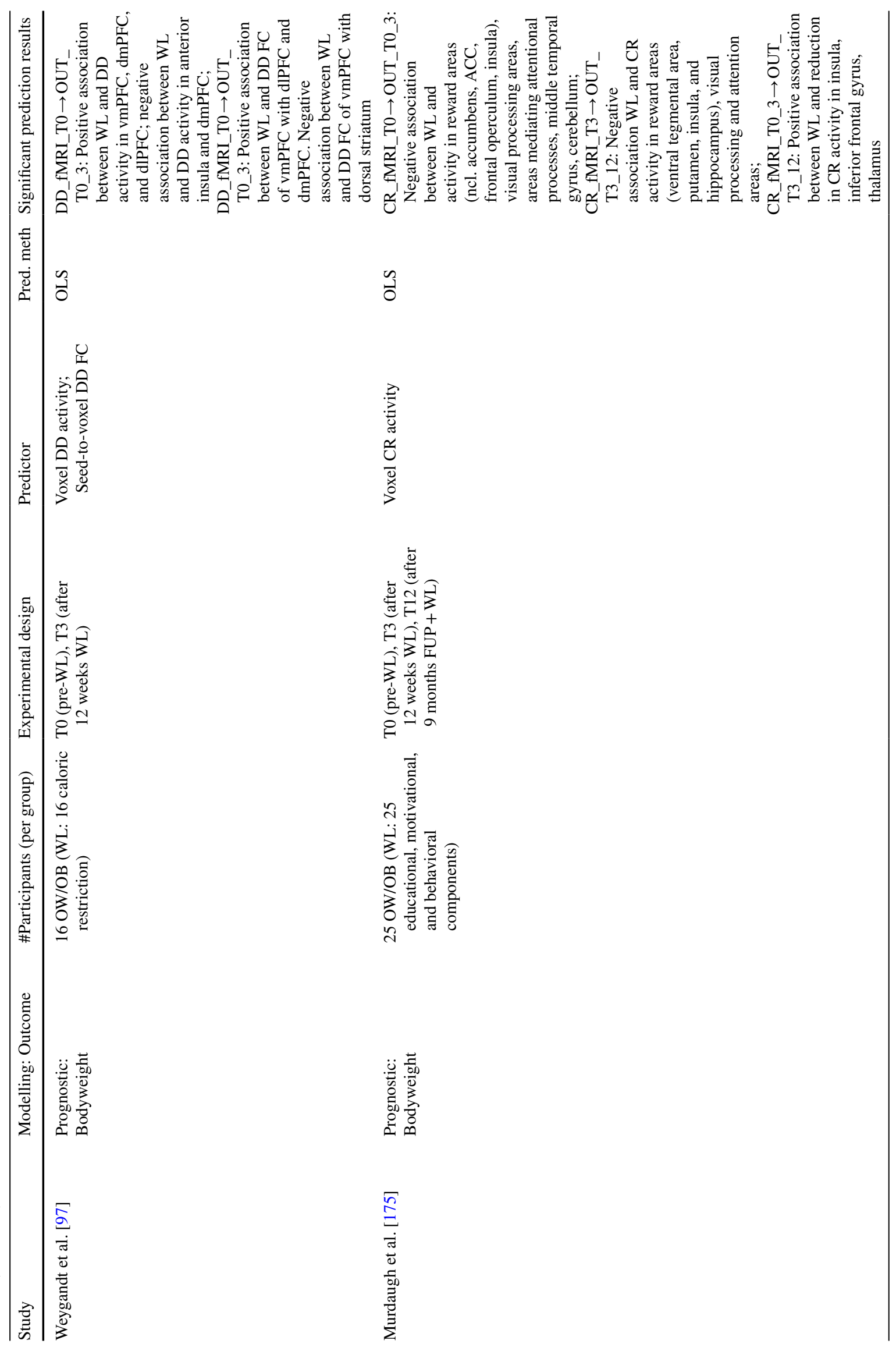




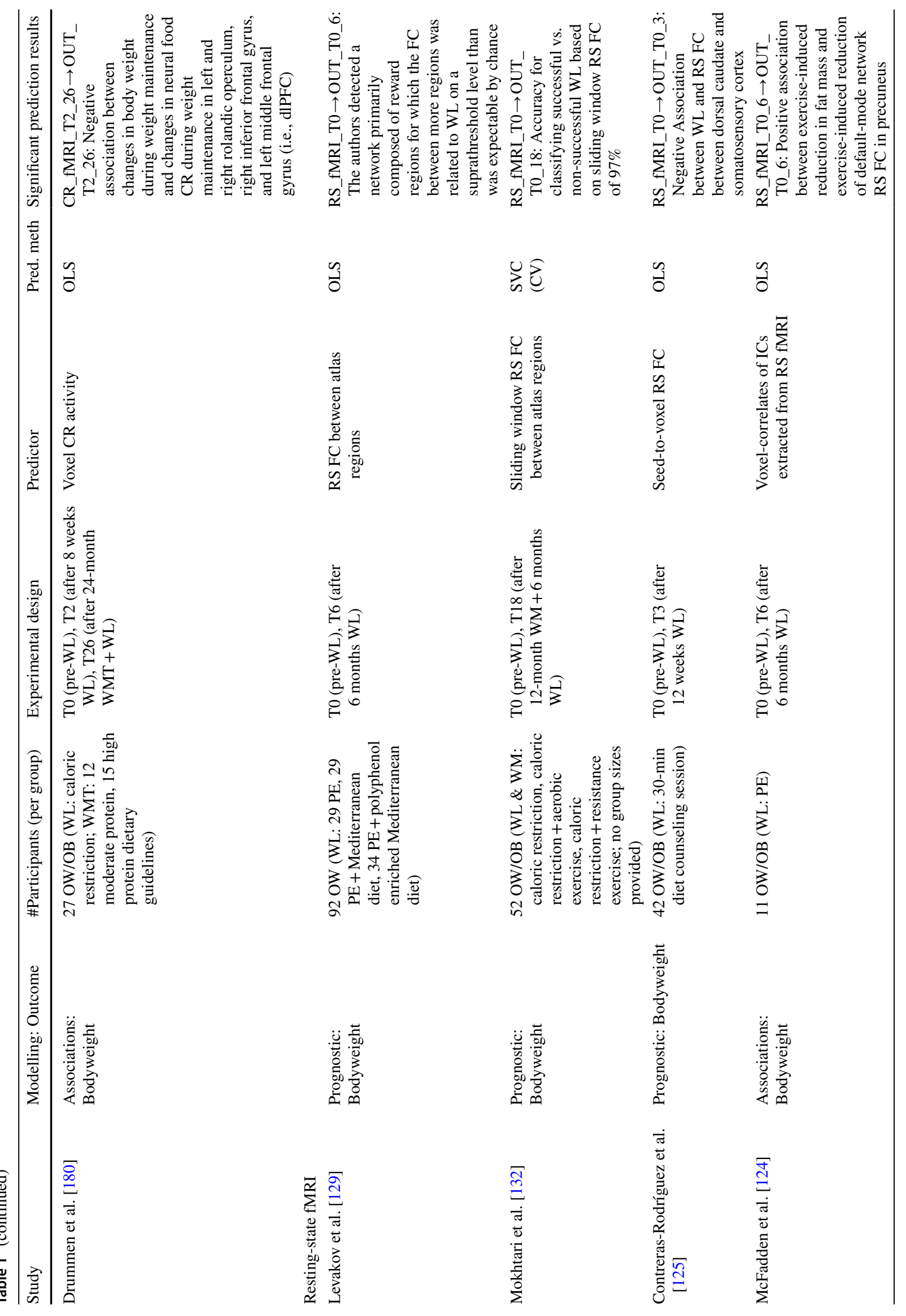




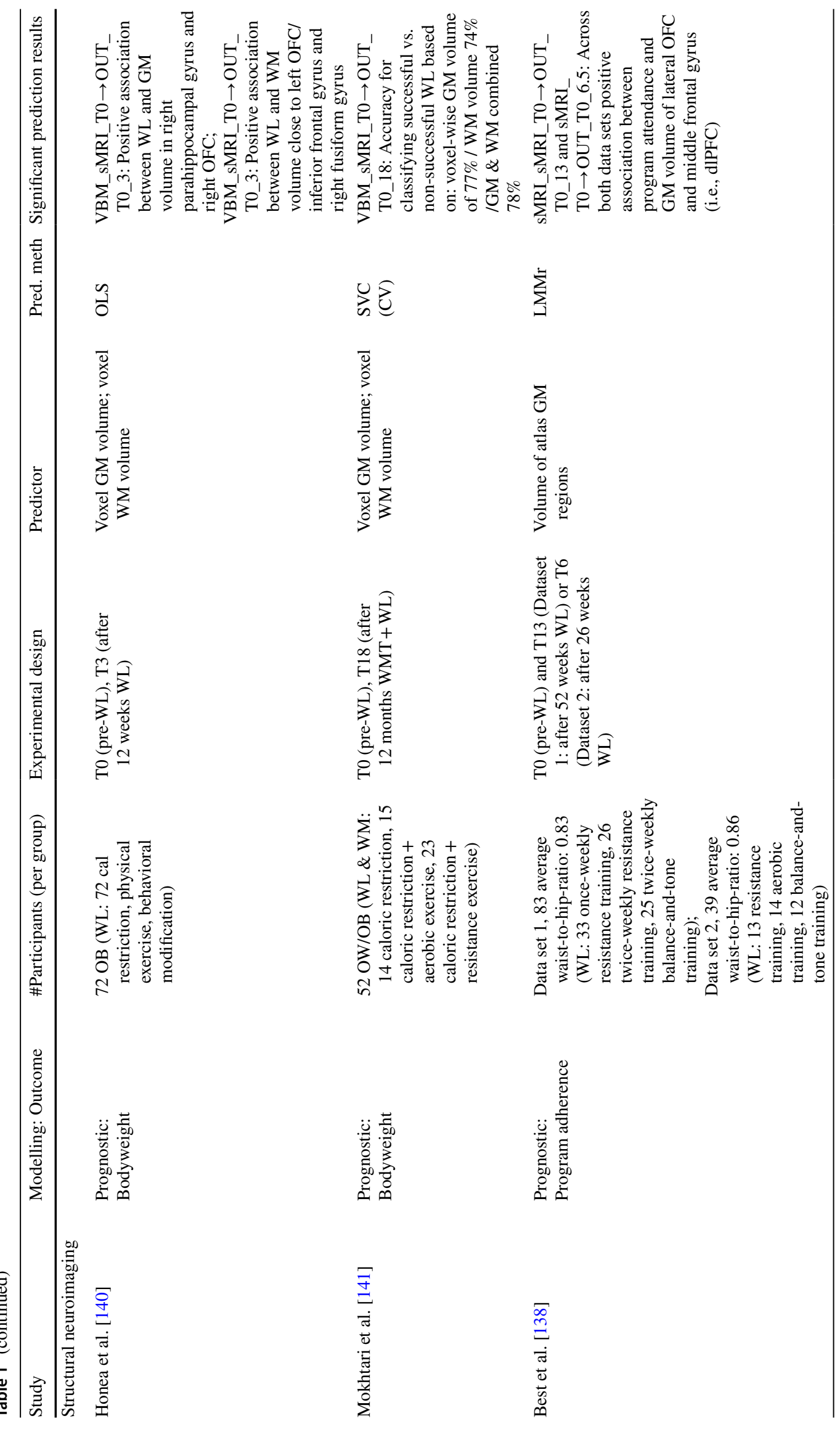




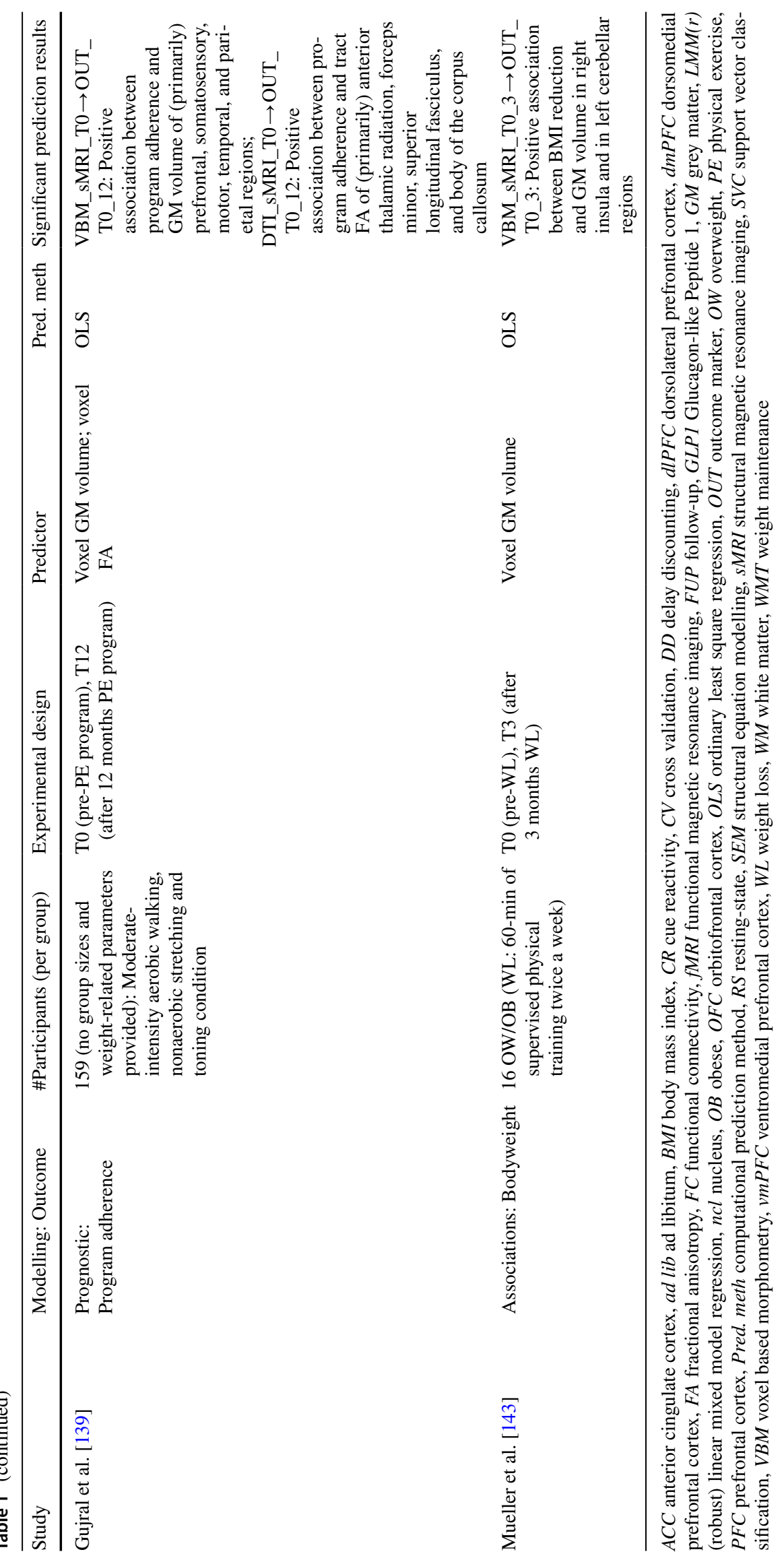




\subsubsection{Independent component analysis}

Independent component analysis is a statistical method that identifies RS networks by computing so-called independent components (ICs). These are transformations of the multivariate voxel input data which are stochastically independent (and not only mutually uncorrelated as in principal component analysis) and can be understood as characteristic RS voxel time series (e.g., [122]). One IC reflects the activity time course of one RS network. After the ICs are identified, they can either be related to treatment outcome directly as in [123] or relations between ICs/RS networks of interest and voxel-wise RS fMRI time courses are determined using participant-specific voxel-wise regression analysis. The resulting correlation/regression coefficients are finally handed over for a group analysis [124].

\subsubsection{Seed-to-voxel functional connectivity}

The seed-to-voxel FC for RS fMRI ("Seed-to-voxel RS FC") applied by [125-127] is technically identical to its taskrelated counterpart described above.

\subsubsection{Functional connectivity between anatomical atlas regions}

FC for prediction has also been computed based on time series averaged across voxels located in anatomical atlas regions [111, 128-132]. Using averaged regional time series requires less priori knowledge as one can simply compute the FC between all atlas regions. Another advantage might be the method's relative robustness to outlier voxels through spatial averaging. However, the method does not make full use of the spatial resolution fMRI is offering.

\subsubsection{Functional connectivity network-analysis}

This (group of) technique(s) aims at characterizing the structure of connected units interacting in complex social, economic, genetic, or neural networks [133]. One major aim is to assess the efficiency of network information flow [134]. Independent of the domain (e.g., social or biological) these techniques have shown that networks with a "small-world" structure (i.e., having a dense local and a sparse long-range connectivity) are both globally and locally efficient with regard to information flow because the average distance between any pair of units (here: brain regions) in such a network is small [135]. One of the reviewed studies [101] utilized a network technique for treatment outcome prediction. Specifically, these authors computed FC using the technique described in 3.2.5 for individual participants first and then determined the global efficiency (see [134]) for each participant-specific FC pattern for prediction.

\subsection{Neurotransmission assessed with Positron-Emission-Tomography}

Positron-Emission-Tomography (PET) is a technique allowing to measure biochemical and physiological activity across biological tissues on a voxel-level by applying radio-tracers (e.g., $\left[{ }^{11} \mathrm{C}\right]$ raclopride and $\left[{ }^{11} \mathrm{C}\right]$ carfentanil) (employed in two reviewed studies $[72,73]$ ). This method can be used in a task-related or RS fashion and has been applied extensively in obesity research to measure transmission of DA and other neurotransmitters (e.g., [15, 57-60]). Steele et al. related Roux-en-Y gastric bypass (RYGB)-induced D2R availability changes to weight loss in a 6-week period after surgery and report a positive association [72]. Karlsson et al. related presurgical $\mu$-opioid receptor and D2R availability to post-BS weight [73]. While no associations were found for D2R, especially amygdala $\mu$-opioid receptor availability was negatively associated to future body weight.

\subsection{Structural neuroimaging}

\subsubsection{Brain tissue volume}

One of the most frequently evaluated tissue properties in structural neuroimaging in general and in the reviewed structural studies specifically [136-143] is voxel-wise tissue volume. Except for Best et al. [138], Voxel-Based Morphometry (VBM; [144]) was used in these studies for computation. VBM is implemented in SPM12 (Wellcome Trust Centre for Neuroimaging, Institute of Neurology, UCL, London UK http://www.fil.ion.ucl.ac.uk/spm). In VBM, anatomical brain images are spatially registered to an anatomical reference space and segmented into the three tissue types grey matter (GM), white matter (WM), and cerebrospinal fluid (CSF). By additionally considering the amount of local deformation applied during spatial registration, the method produces markers of the voxel-wise volume for each of the three tissue types (referred to as "Voxel GM or WM volume" in the following). Contrary to VBM, the method used by Best et al. [138] computes volumes for larger regions included in an anatomical atlas and is implemented in FreeSurfer [145, 146]. For a method comparison, see Guo et al. [147].

\subsubsection{Cortical thickness}

Another structural brain property evaluated frequently in structural neuroimaging in general and in one reviewed studies [148] is cortical thickness (implemented e.g., in FreeSurfer [146]). In short, this parameter is computed by determining the WM/GM transition surface and the GM/ pial transition surface in a first step and by determining the distance between these two surfaces for small spatial units ("vertices") in a second. 


\subsubsection{Brain diffusion}

Diffusion MRI enables evaluating brain fiber characteristics by assessing directions of water molecule diffusion and was applied in two of the reviewed studies [99, 139]. Specifically, utilizing the fact that water can diffuse equally into any direction in unstructured spaces such as CSF but only in directions predetermined by biological structures and their integrity in neural tissues, measurement and modelling of water molecule diffusion allows evaluating axon bundle orientation and integrity [149]. A method frequently used for this purpose is Diffusion Tensor Imaging (DTI). In DTI, water molecule diffusion is measured for a predefined number of diffusion orientations. Subsequently, participant- and time point-specific voxel maps reflecting different diffusion properties are determined by fitting an ellipsoid to the threedimensional diffusion information. The two most important fiber characteristics derived thereof are Fractional Anisotropy, which can be understood as the degree of diffusion directedness, and Mean Diffusivity, a measure of overall diffusivity. Finally, a method complementing DTI is fiber tractography which aims at tracing WM tracts based on the directional information provided by diffusion-weighted MRI. One of the reviewed studies applied tractography [99]. Soares et al. provides an overview on DTI and tractography including a list of available software packages [150], MaierHein et al. highlights pitfalls in tractography [151].

\section{Computational prediction approaches}

This section describes the methods used for assessing treatment outcome on the group level across the reviewed studies. Except for ordinary least squares (OLS) regression, these methods are illustrated in Fig. 2.

\subsection{Linear regression}

\subsubsection{Ordinary least square regression}

The technique used for treatment outcome prediction on the group level in the majority of reviewed studies is voxel-wise OLS regression. This technique is implemented in a variety of software packages such as SPM, FMRIB Software Library (FSL) [152], Analysis of Functional NeuroImages (AFNI; http://afni.nimh.nih.gov/afni) [153], or BrainVoyager (http://www.brainvoyager.com/) [154]. OLS regression identifies an optimal set of regression coefficients by minimizing the sum of squared differences between true and predicted values for the dependent variable (e.g., weight loss obtained in a certain interval or brain activity in a certain voxel). Given that multiple voxels are tested, methods correcting for family-wise error (e.g., the Random Field Theory,
Fig. 2 illustrates computational approaches used for treatment outcome prediction on the group level. In particular, (a) illustrates the LMM regression approach and is taken from [18]. (b) depicts an application of support vector classification for a hypothetical classification task in which a classifier has to learn the differences between voxel GM patterns belonging to very successful dieters and less successful dieters in the training stage. In the next step, the classification boundary estimated from the training data is used to predict the class of an unknown test person based on their GM pattern. (b) is derived from Weygandt et al. [172]. Finally, (c) shows a hypothetical structural equation model (in part derived from [169])

Bonferroni, or the maximum statistic method [155-157]) have to be applied to evaluate the significance of individual voxels' tests. A drawback in a longitudinal framework is the method's sensitivity to drop-out, as participants have to be excluded completely once a single time point is missing (for further points, see e.g. [158, 159]).

\subsubsection{Linear mixed model regression}

Linear mixed models (LMMs; implemented in Freesurfer $[160,161]$ are a newer regression method [162] that has been applied in four reviewed studies [18, 136, 138, 163]. LMM regression models the variation in the criterion (e.g., weight loss) as a linear combination of fixed and random effects. The former correspond to parameters that can be defined freely by the researcher (e.g. group membership), the latter to parameters for which this is not possible because they vary in an endogenous, participant-specific fashion (e.g., participants' signal means or trends). LMM regression has several properties that makes it a suitable candidate for the analysis of longitudinal study designs. First, it can model a signal sampled across an arbitrary number of time points simultaneously. Second, it can handle designs which are unbalanced due to participant drop out [162] and has thus has higher statistical power than alternative methods (e.g., repeated measures analysis of variance based on OLS regression) because participants with partially missing data need not to be excluded [161]. It has been shown that even the inclusion of participants with only a single data point can improve the accuracy of LMM regression [161]. Finally, unlike repeated measures analysis of variance, LMM regression is able to cope flexibly with varying data covariation across time.

\subsection{Support vector classification}

Support vector classification (SVC) is a supervised classification approach used in the majority of reviewed studies employing machine learning (i.e., $[132,141])$. A third study employed a combination of Twin networks and k-nearest neighbor clustering [130]. Given the rare use of this approach in neuroimaging, we would like to point 
a

$\begin{gathered}\text { Participant ID, } \\ \text { time point }\end{gathered}$
ID 1, T-3

b

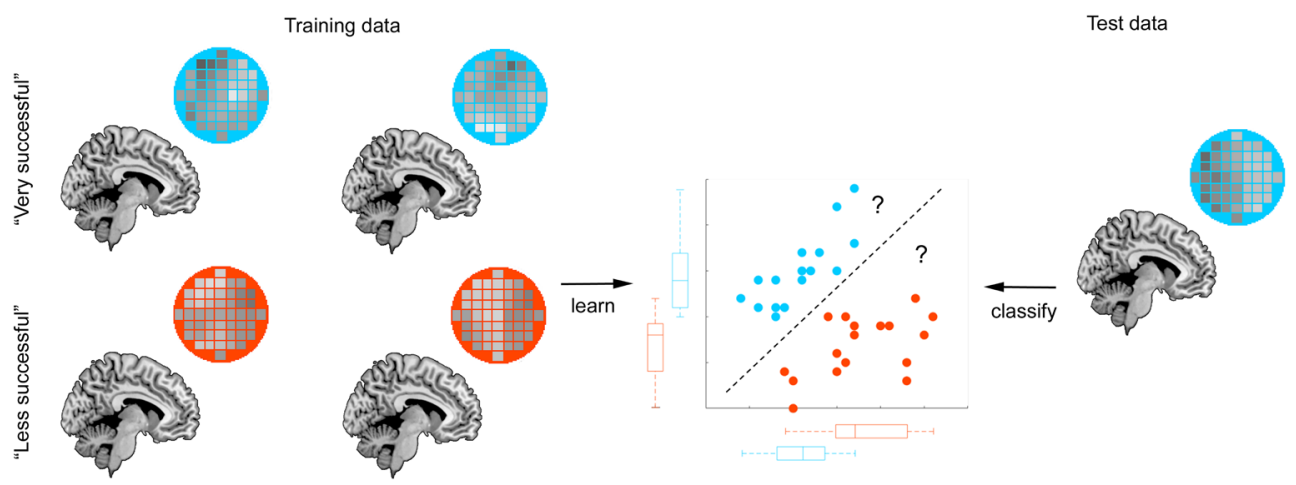

C

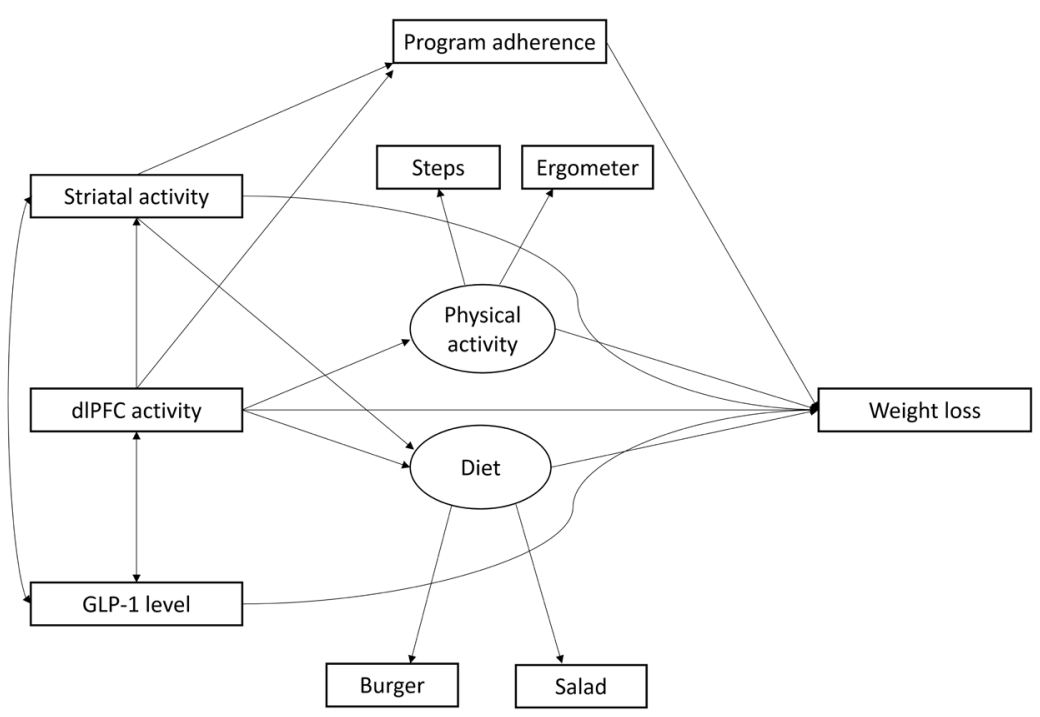


the reader directly to this study for details. In supervised classification, a machine learning algorithm tries to learn characteristic properties from (e.g., brain activity) patterns representative of different classes (e.g., successful vs. non-successful dieters) in a training stage. In its basic form, the SVC algorithm does so by identifying a linear class boundary ("classification model") that separates the training patterns of two classes and which optimizes the trade-off between the number of non-separable patterns and classifier complexity [164]. In the test or model validation stage, the model is evaluated by computing a classification accuracy measure for unseen test data. Model validation techniques range from leave-one-out cross validation (LOO-CV) to out-of-sample validation. One important aspect arising from this variety and other factors such as a putative sensitivity of supervised classification to sample size [165] is the use of resampling techniques for inference. These consider the conditions under which the empirical classification accuracy is obtained. Parametric procedures do not possess this property (e.g., $[166,167])$.

\subsection{Structural equation modelling}

Structural equation modelling [168] is a multivariate analysis technique applied in one reviewed study [169] evaluating whether/how well the relations among hypothesized constructs fit to relations among ("latent" or unobservable) mathematical factors representing these constructs extracted from a set of ("manifest" or observable) empirical data. In structural equation modelling, relations between manifest variables and latent constructs (i.e., the "measurement model") and among latent constructs ("latent variable model") have to be specified first. It is possible to specify directed effects in the latent variables model and thus to assume causal relations among variables (see below). Although structural equation modelling is a very flexible and powerful tool, several aspects have to be taken into consideration. Structural equation modelling cannot be used to test causal relations among constructs. Instead, structural equation modelling tests whether associations in a specific empirical data set fit to the causal assumptions held by the researcher. Poor model fits will strongly question the validity of these assumptions. However, good model fits will increase their plausibility, but not prove them, and require replication on independent data sets [170]. The sensitivity of structural equation modelling to variations in sample size and to violations of distributional assumptions remains a limiting factor. Methods to deal with these problems have e.g., been presented by Kock \& Hadaya [171] and Hox et al. [172]. See [172] for an overview.

\section{Study overview}

Here we provide a tabular overview of the reviewed studies. Table 1 gives an overview on LI-based studies, Table 2 on BS-based studies and Table 3 on PI-based studies.

\section{Discussion}

In this study, we review current work on computational approaches to predicting treatment response in obesity using neuroimaging. We started by outlining key CNS mechanisms thought to affect treatment outcome and then described the neuroimaging techniques and parameters as well as computational approaches used for prediction. Lastly, we gave an overview on existing studies.

This overview provided a consistent picture on the role of CNS mechanisms for treatment outcome in obesity. For example, the importance of dopaminergic reward areas was underlined by CR studies showing that cue-evoked activity in these areas is negatively related to treatment outcome [173-177]. The relevance of goal-directed control regions comprising frontal and parietal areas as well as insula was demonstrated in DD tasks directly designed to study goal-directed control $[18,97,104,106]$ and in CR tasks by showing that cue-related activity of these areas has a positive effect on treatment outcome [86, 169, 178-180]. Task-derived FC and RS FC studies showed that higher FC between fronto-parietal and insular goaldirected control areas on one hand and incentive salience areas on the other is accompanied by better treatment outcomes [18, 97, 99, 100, 126]. Obesity-related regions involved in incentive salience and goal-directed control as identified by task fMRI strongly overlap with obesityrelated regions as identified via RS FC [181]. These results were complemented by structural neuroimaging studies $[99,137-140,142,143]$ showing that higher GM volume of goal directed areas was associated with better treatment outcome and higher GM volume of incentive salience regions with worse outcome.

Some studies did not support a link between incentive salience or goal-directed control and treatment outcome. The fMRI studies of Bach et al. and Ten Kulve et al. did not show such a link $[85,86]$. In addition, associations between cortical thickness of the superior frontal gyrus and weight loss reported by Liu et al. did not reach a multiple comparison corrected significance level [148]. Similarly, a couple of behavioral studies (not properly controlling for well-known nuisance factors) failed to identify reduced goal-directed control in obesity (e.g., [94, 95]). Thus, due to these null results and the possibility of a 


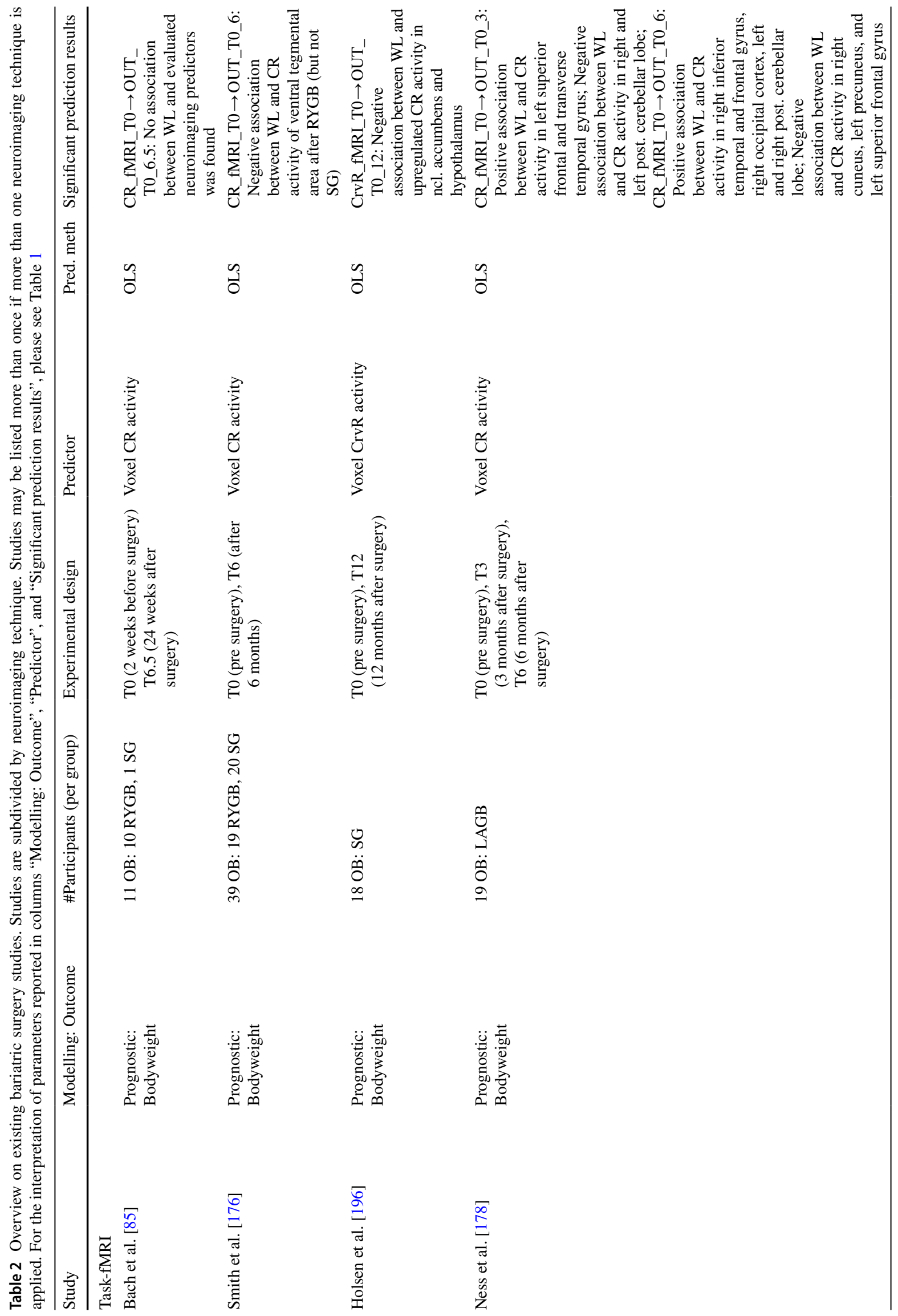




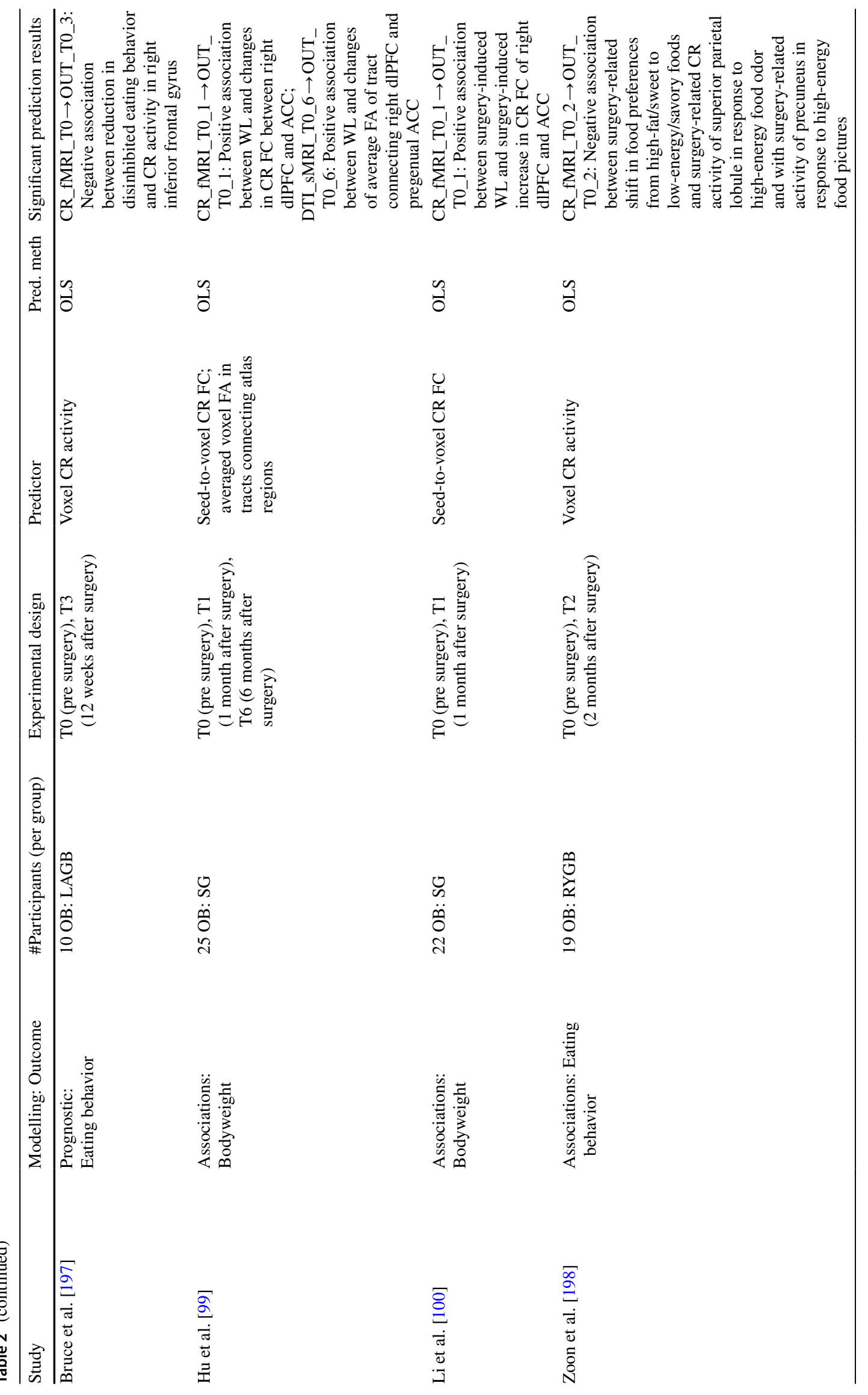




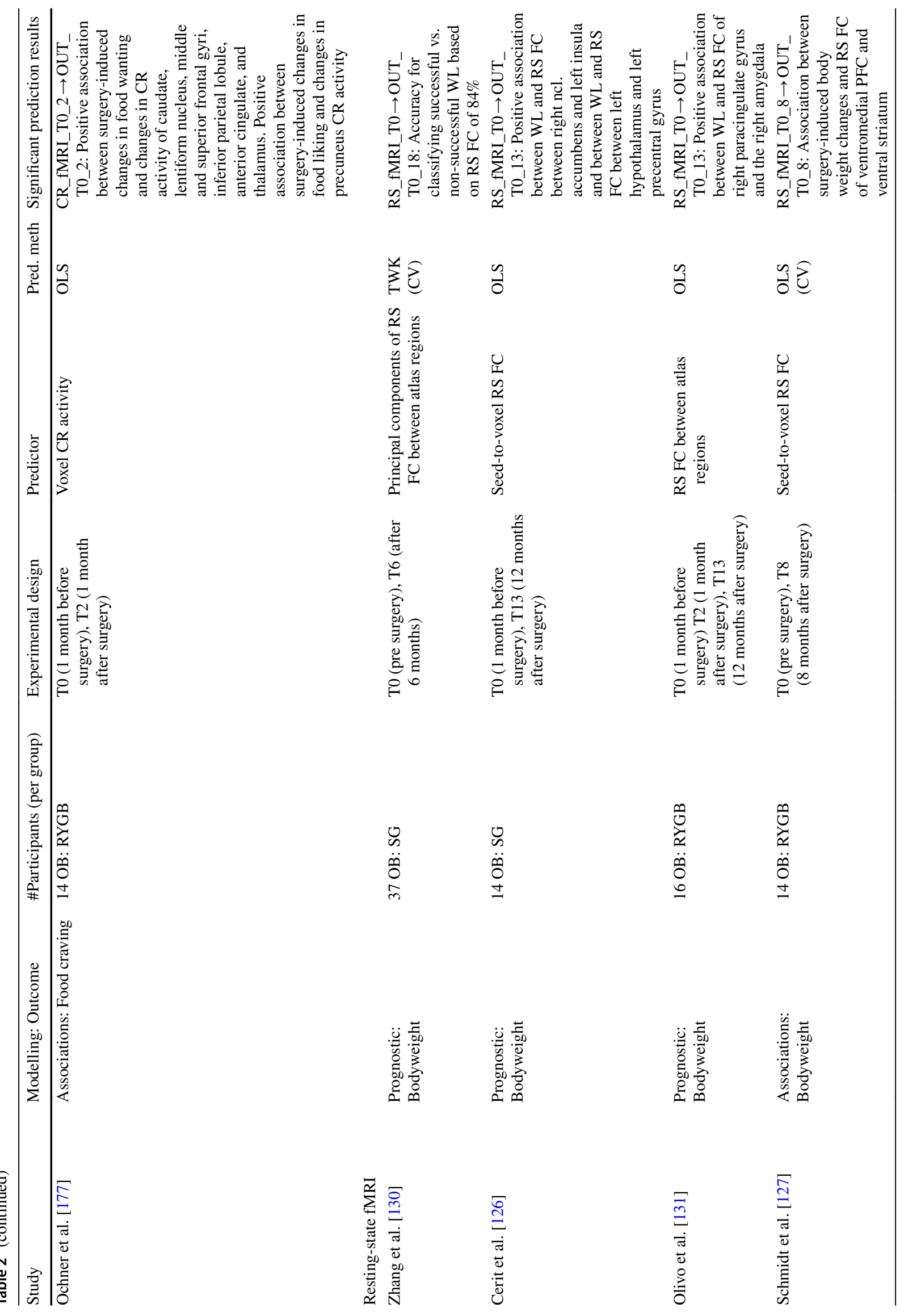




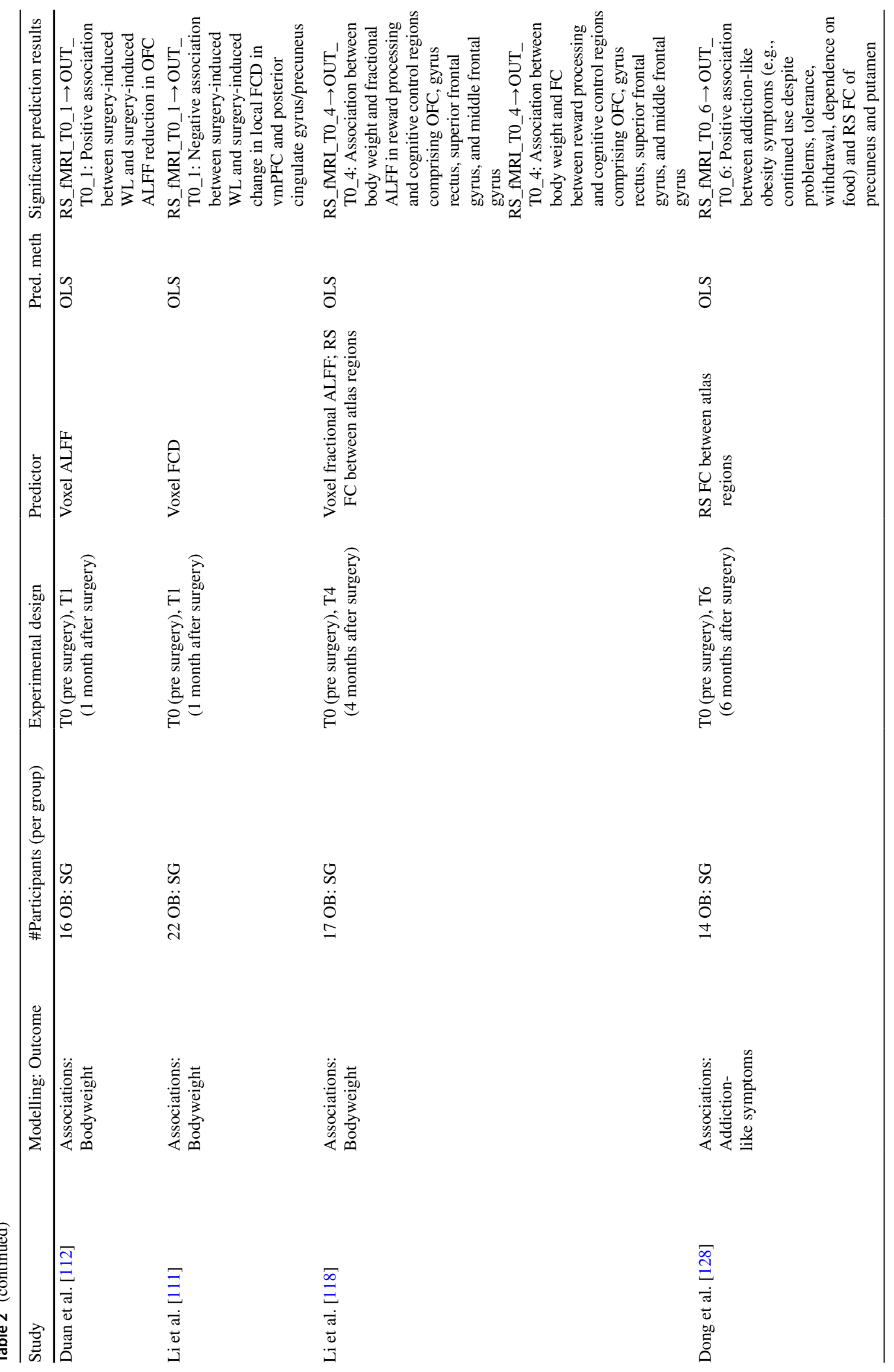




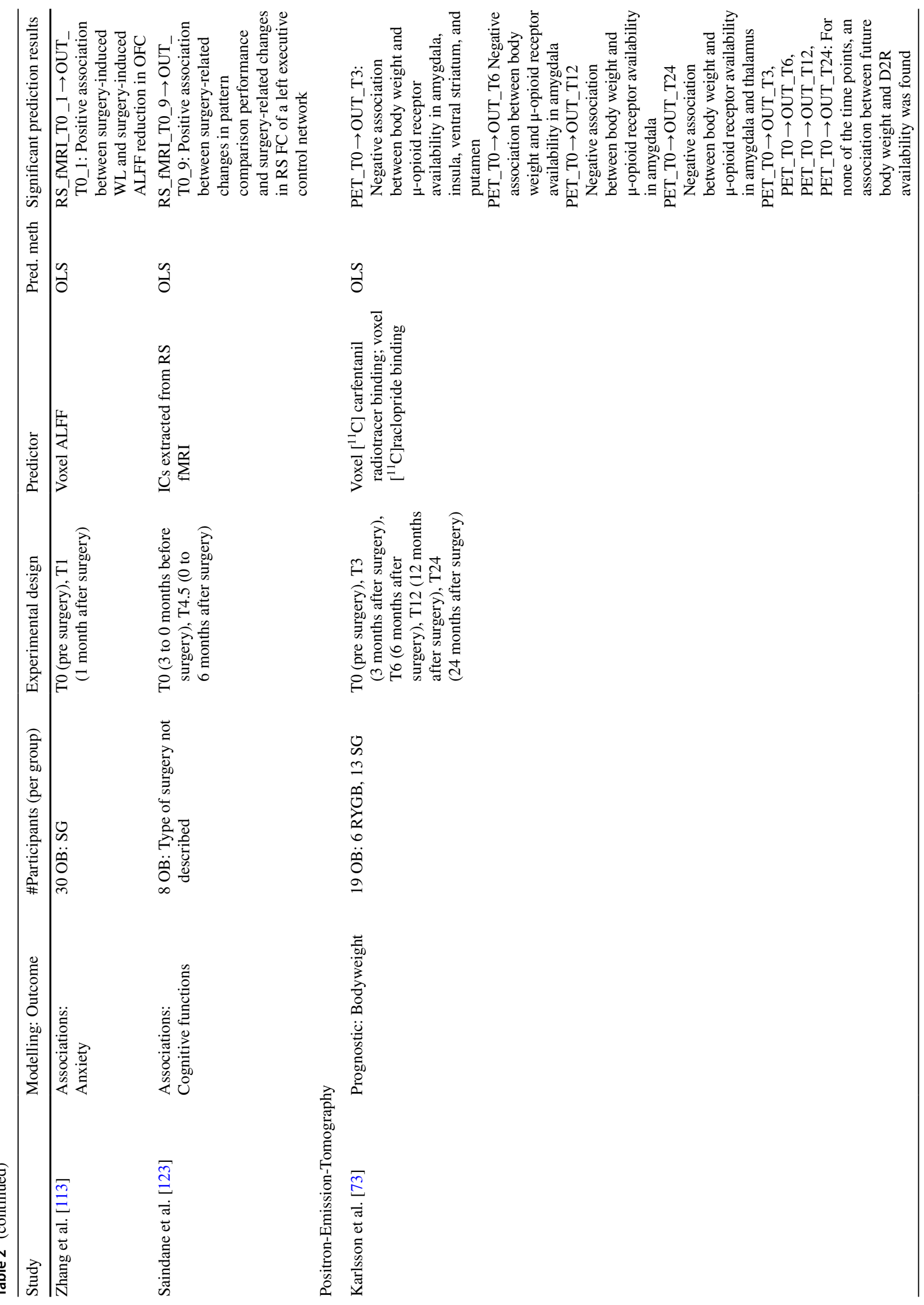




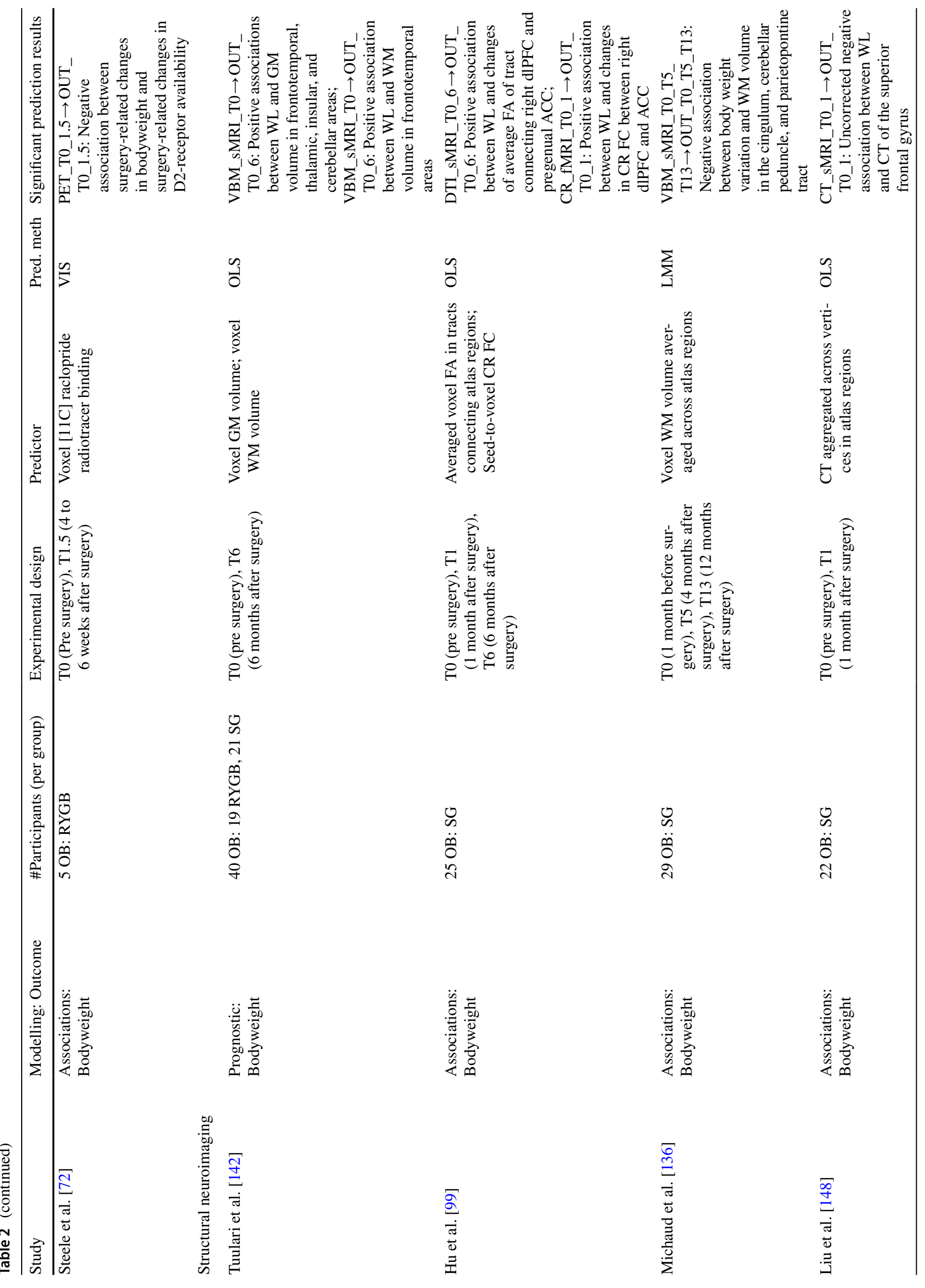




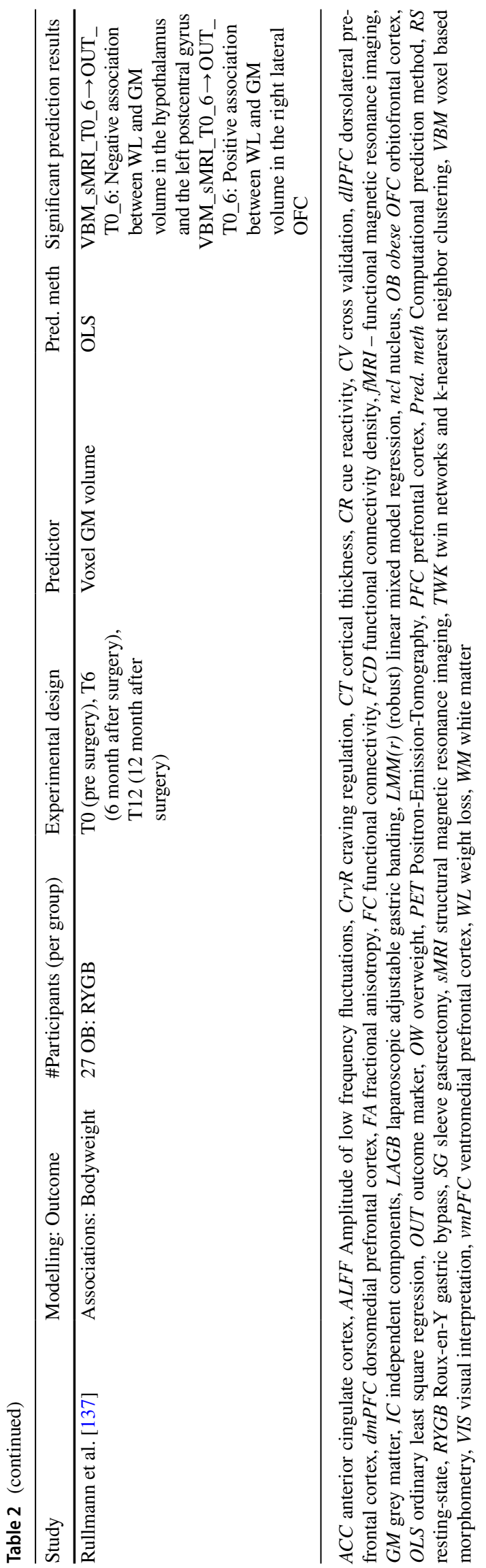

publication bias [182], the large number of consistent findings mentioned have to be viewed in a critical light. Nevertheless, given that the concepts of incentive salience and goal-directed control are derived from basic neuroscience on reward and motivation (e.g., $[75,76]$ ), it can be assumed that these two CNS mechanisms play an important role for treatment outcome in obesity.

Do the presented findings also allow us to conclude that the evaluated neuroimaging predictors yield suitable biomarkers for obesity treatment outcome in a real-world precision medicine approach? Such a conclusion might be premature. An important counter argument is that the majority of studies applied correlational techniques evaluating all available data in one step (instead of applying model validation techniques) to analyze many predictors for one criterion assessed in small to moderately sized samples. This approach is sensitive to over- (and under-) fitting [183]. If the number of predictors is high (e.g., as in voxel-wise analyses) and the number of participants small, a statistical model for a criterion can occasionally fit this criterion well (poorly) because the predictor is not very reliable or varies substantially across different measurements. Thus, although such correlational analyses yield valid statistical inference on the group level if the analyses adequately controlled for multiple comparisons and were not circular [184, 185], their results might not be generalizable to unseen data and would not yield suitable biomarkers. Consequently, suitable biomarkers have to have a high retest-reliability.

How reliable are which neuroimaging parameters? What can be done to improve data reliability? How can a high generalizability of a prognostic model to unseen data be ensured? Meta-analyses provide answers to the first question. Studies assessing the reliability of task fMRI (typically via the intraclass correlation (ICC; [186]) for which a poor reliability was defined as ICC $<0.4$, a fair as $0.4 \leq$ ICC $<0.59$, a good one as $0.6 \leq \mathrm{ICC}<0.75$, and an excellent as ICC $\geq 0.75$ [187]) reported an average ICC of 0.5 ([188]; $\mathrm{N}=15)$ or 0.397 ([189]; $\mathrm{N}=56$ ). A meta-analysis assessing retestreliabilities for RS FC found an average ICC of 0.29 ([190]; $\mathrm{N}=25$ ). Consistent with Han et al. [191], retest-reliabilities computed for volume- and surface-based structural neuroimaging parameters by Elliott et al. showed primarily excellent ICCs [189]. Thus, together with the fact that structural neuroimaging parameters were significantly related to treatment outcome, these findings show that structural neuroimaging parameters might provide the most suitable biomarkers.

However, it is unclear to which degree the reliabilities reported for task fMRI and RS FC can be generalized. First, clinical studies applying specific tasks due to disease-related theoretical or empirical reasons were severely underrepresented in these meta-analyses. Second, especially for Elliott et al., the average retest interval was quite long (four months) given that Bennett \& Miller found that studies with three or more months 
Table 3 Overview on existing pharmacological intervention studies. For the interpretation of parameters reported in columns "Modelling: Outcome", "Predictor", and "Significant prediction results", please see Table 1

\begin{tabular}{|c|c|c|c|c|c|c|}
\hline Study & Modelling Outcome & $\begin{array}{l}\text { \#Participants (per } \\
\text { group) }\end{array}$ & Experimental design & Predictor & Pred. meth & $\begin{array}{l}\text { Significant prediction } \\
\text { results }\end{array}$ \\
\hline \multicolumn{7}{|l|}{ Task-fMRI } \\
\hline Ten Kulve et al. [86] & $\begin{array}{l}\text { Prognostic: } \\
\text { Bodyweight }\end{array}$ & $\begin{array}{l}20 \text { OW/OB: } \\
\text { Liraglutide (vs. } \\
\text { Insulin; cross-over } \\
\text { design) }\end{array}$ & $\begin{array}{l}\text { T0 (before } \\
\text { treatment), T0.3 } \\
\text { (after } 10 \text { days of } \\
\text { treatment), T3 } \\
\text { (after } 12 \text { weeks of } \\
\text { treatment) }\end{array}$ & Voxel CR activity & OLS & $\begin{array}{l}\text { CR_fMRI_ } \\
\text { T0.3_3 } \rightarrow \text { OUT_ } \\
\text { T0_12: No } \\
\text { association between } \\
\text { WL and evaluated } \\
\text { neuroimaging } \\
\text { predictors was } \\
\text { found }\end{array}$ \\
\hline $\begin{array}{l}\text { Ten Kulve et al. } \\
\text { [199] }\end{array}$ & $\begin{array}{l}\text { Prognostic: } \\
\text { Bodyweight }\end{array}$ & $\begin{array}{l}20 \text { OW/OB: } \\
\text { Liraglutide (vs. } \\
\text { Insulin; cross-over } \\
\text { design) }\end{array}$ & $\begin{array}{l}\text { T0 (before } \\
\text { treatment), T0.3 } \\
\text { (after } 10 \text { days of } \\
\text { treatment), T3 } \\
\text { (after } 12 \text { weeks of } \\
\text { treatment) }\end{array}$ & Voxel CR activity & OLS & $\begin{array}{l}\text { CR_fMRI_ } \\
\text { T0.3 } \rightarrow \text { OUT__ } \\
\text { T0_12: Positive } \\
\text { association between } \\
\text { WL and higher CR } \\
\text { activity in right } \\
\text { insula after } \\
\text { liraglutide vs. after } \\
\text { insulin }\end{array}$ \\
\hline
\end{tabular}

$C R$ cue reactivity, $f M R I$ functional magnetic resonance imaging, $O B$ obese, $O L S$ ordinary least square regression, $O U T$ outcome marker, $O W$ overweight, Pred. meth computational prediction method, $W L$ weight loss

had reduced retest-reliability $[188,189]$. The latter finding is consistent with the fact that retest-reliability is affected by a biomarker's noise as well as by noise-independent physiological alterations occurring over time [192].

Irrespective of whether or not these meta-analyses provide extremely accurate estimates of retest-reliability for fMRI-derived markers, there is space for improvement. Consequently, one might ask what to do to improve reliability? Circumstances enabling an accurate reliability estimation are an important prerequisite. Given that retestreliability is negatively associated with the duration of the retest-interval [192], an unbiased estimate requires a short time interval. A cross-sectional estimation procedure with zero interval length might be optimal in this regard which computes reliability based on several data subsets of a single scanning session [193]. Given that fMRI data reflect a highly complex process and are sensitive to a broad range of confounding factors, improvements should aim at adequately reducing factors such as head motion, breathing, heart rate, hydration, satiation, neuromodulators including caffeine or nicotine (e.g., [183]). Specific improvements for FC comprise increasing the number of acquired fMRI scans [189, 190] and combining RS FC data acquired across extended scan sessions with complementary task-fMRI data [189]. Additionally, FC computation based on a natural viewing tasks yielded fair to excellent reliability in a study of Wang et al. and was significantly higher than that derived from RS [194].
Another step to optimize neuroimaging-based treatment outcome prediction for clinical application would aim at maximizing the generalizability of a prognostic model to unseen data via application of model validation techniques. In this approach, different models (e.g., derived from neural networks, support vector classifiers, etc.) would be trained on a set of training data. Selection of features yielding a high prognostic accuracy could then be performed for each model separately using independent evaluation data. The prognostic performance is then tested once for each model based on independent test data and the best is selected for application (e.g., [183]).

Consequently, access to highly reliable biomarkers derived from adequately powered studies using model validation techniques is an important prerequisite for using neuroimaging-derived biomarkers for applied treatment outcome prediction in clinical practice - a prerequisite that might not be met today. Besides these application-related aspects, further improvements could entail a more elaborate modelling of "treatment-outcome". This would take multiple neuroimaging, hormonal, and outcome markers (see e.g., $[18,163,179])$ into consideration. In this regard, the study of Szabo-Reed and colleagues might be pioneering as complex associations between brain activity, caloric restrictions, program attendance, physical activity and weight loss were modeled within a single structural equation model in this work [169]. This approach does not only promise to reveal a more fine-grained picture of contributing factors but also 
to facilitate a comparison of prediction accuracy obtained by different biomarker compilations.

In conclusion, the reviewed studies provide consistent support for the importance of incentive salience and goaldirected control as central nervous mechanisms mediating treatment outcome in obesity. Despite these findings, larger studies using statistical methods optimized with regard to real-world outcome prediction are needed to determine whether the approach is sufficiently accurate for application in a personalized medicine framework.

Funding Open Access funding enabled and organized by Projekt DEAL. The work was supported by the German Research Foundation (WE 5967/2-1 and WE 5967/2-2 to MW). Our funding sources did not influence the study design, the collection and interpretation of studies, the writing of the report or the decision to submit the article for publication. Deutsche Forschungsgemeinschaft, WE 5967/2-1, Martin Weygandt, WE 5967/2-2, Martin Weygandt.

Data availability Not applicable.

Code availability Not applicable.

\section{Declarations}

Conflicts of interest None of the authors (i.e., Leonard Kozarzewski, Lukas Maurer, Anja Mähler, Joachim Spranger, Martin Weygandt) has a biomedical financial interest or potential conflict of interest in the context of this work.

Open Access This article is licensed under a Creative Commons Attribution 4.0 International License, which permits use, sharing, adaptation, distribution and reproduction in any medium or format, as long as you give appropriate credit to the original author(s) and the source, provide a link to the Creative Commons licence, and indicate if changes were made. The images or other third party material in this article are included in the article's Creative Commons licence, unless indicated otherwise in a credit line to the material. If material is not included in the article's Creative Commons licence and your intended use is not permitted by statutory regulation or exceeds the permitted use, you will need to obtain permission directly from the copyright holder. To view a copy of this licence, visit http://creativecommons.org/licenses/by/4.0/.

\section{References}

1. Schienkiewitz A, Mensink GB, Scheidt-Nave C. Comorbidity of overweight and obesity in a nationally representative sample of German adults aged 18-79 years. BMC Public Health. 2012;12:658. https://doi.org/10.1186/1471-2458-12-658.

2. Eckel RH. Obesity and heart disease: a statement for healthcare professionals from the Nutrition Committee. American Heart Association Circulation. 1997;96(9):3248-50. https://doi.org/10. 1161/01.cir.96.9.3248.

3. Renehan AG, Zwahlen M, Egger M. Adiposity and cancer risk: new mechanistic insights from epidemiology. Nat Rev Cancer. 2015;15(8):484-98. https://doi.org/10.1038/nrc3967.
4. Fontana L, Hu FB. Optimal body weight for health and longevity: bridging basic, clinical, and population research. Aging Cell. 2014;13(3):391-400. https://doi.org/10.1111/acel.12207.

5. Luppino FS, de Wit LM, Bouvy PF, Stijnen T, Cuijpers P, Penninx BW, et al. Overweight, obesity, and depression: a systematic review and meta-analysis of longitudinal studies. Arch Gen Psychiatry. 2010;67(3):220-9. https://doi.org/10.1001/archgenpsychiatry. 2010.2 .

6. Ha H, Han C, Kim B. Can Obesity Cause Depression? A Pseudopanel Analysis. J Prev Med Public Health. 2017;50(4):262-7. https://doi.org/10.3961/jpmph.17.067.

7. Gariepy G, Nitka D, Schmitz N. The association between obesity and anxiety disorders in the population: a systematic review and meta-analysis. Int J Obes (Lond). 2010;34(3):407-19. https://doi. org/10.1038/ijo.2009.252.

8. Christakis NA, Fowler JH. The spread of obesity in a large social network over 32 years. N Engl J Med. 2007;357(4):370-9. https://doi.org/10.1056/NEJMsa066082.

9. Bouchard C. Genetics of Obesity: What We Have Learned Over Decades of Research. Obesity (Silver Spring). 2021;29(5):80220. https://doi.org/10.1002/oby.23116.

10. Makaronidis JM, Batterham RL. The role of gut hormones in the pathogenesis and management of obesity. Curr Opin Physio. 2019;12:1-11. https://doi.org/10.1016/j.cophys.2019.04.007.

11. Brytek-Matera A, Czepczor-Bernat K, Olejniczak D. Foodrelated behaviours among individuals with overweight/obesity and normal body weight. Nutr J. 2018;17(1):93. https://doi.org/ 10.1186/s12937-018-0401-7.

12. Swinburn BA, Caterson I, Seidell JC, James WP. Diet, nutrition and the prevention of excess weight gain and obesity. Public Health Nutr. 2004;7(1a):123-46. https://doi.org/10.1079/phn2003585.

13. Jebb SA, Moore MS. Contribution of a sedentary lifestyle and inactivity to the etiology of overweight and obesity: current evidence and research issues. Med Sci Sports Exerc. 1999;31(11 Suppl):S534-41. https://doi.org/10.1097/00005768-199911001-00008.

14. Johnson PM, Kenny PJ. Dopamine D2 receptors in addictionlike reward dysfunction and compulsive eating in obese rats. Nat Neurosci. 2010;13(5):635-41. https://doi.org/10.1038/nn.2519.

15. Wang GJ, Volkow ND, Logan J, Pappas NR, Wong CT, Zhu W, et al. Brain dopamine and obesity. Lancet. 2001;357(9253):3547. https://doi.org/10.1016/s0140-6736(00)03643-6.

16. Volkow ND, Wise RA, Baler R. The dopamine motive system: implications for drug and food addiction. Nat Rev Neurosci. 2017;18(12):741-52. https://doi.org/10.1038/nrn.2017.130.

17. Berridge $\mathrm{KC}$, Robinson TE. Liking, wanting, and the incentivesensitization theory of addiction. Am Psychol. 2016;71(8):6709. https://doi.org/10.1037/amp0000059.

18. Weygandt M, Spranger J, Leupelt V, Maurer L, Bobbert T, Mai $\mathrm{K}$, et al. Interactions between neural decision-making circuits predict long-term dietary treatment success in obesity. Neuroimage. 2019;184:520-34. https://doi.org/10.1016/j.neuroimage. 2018.09.058.

19. Rangel A. Regulation of dietary choice by the decision-making circuitry. Nat Neurosci. 2013;16(12):1717-24. https://doi.org/10. 1038/nn.3561.

20. Yumuk V, Tsigos C, Fried M, Schindler K, Busetto L, Micic D, et al. European Guidelines for Obesity Management in Adults. Obes Facts. 2015;8(6):402-24. https://doi.org/10.1159/000442721.

21. Donnelly JE, Blair SN, Jakicic JM, Manore MM, Rankin JW, Smith BK. American College of Sports Medicine Position Stand. Appropriate physical activity intervention strategies for weight loss and prevention of weight regain for adults. Med Sci Sports Exerc. 2009;41(2):459-71. https://doi.org/10.1249/MSS.0b013e3181949333.

22. Washburn RA, Szabo AN, Lambourne K, Willis EA, Ptomey LT, Honas JJ, et al. Does the method of weight loss effect longterm changes in weight, body composition or chronic disease risk 
factors in overweight or obese adults? A systematic review. PLoS ONE. 2014;9(10): e109849. https://doi.org/10.1371/journal.pone. 0109849.

23. Svetkey LP, Stevens VJ, Brantley PJ, Appel LJ, Hollis JF, Loria $\mathrm{CM}$, et al. Comparison of strategies for sustaining weight loss: the weight loss maintenance randomized controlled trial. JAMA. 2008;299(10):1139-48. https://doi.org/10.1001/jama.299.10. 1139.

24. Arterburn D, Gupta A. Comparing the Outcomes of Sleeve Gastrectomy and Roux-en-Y Gastric Bypass for Severe Obesity. JAMA. 2018;319(3):235-7. https://doi.org/10.1001/jama.2017.20449.

25. Vidal J, Corcelles R, Jiménez A, Flores L, Lacy AM. Metabolic and Bariatric Surgery for Obesity. Gastroenterology. 2017;152(7):178090. https://doi.org/10.1053/j.gastro.2017.01.051.

26. Fried M, Yumuk V, Oppert JM, Scopinaro N, Torres A, Weiner $\mathrm{R}$, et al. Interdisciplinary European guidelines on metabolic and bariatric surgery. Obes Surg. 2014;24(1):42-55. https://doi.org/ 10.1007/s11695-013-1079-8.

27. Cadena-Obando D, Ramírez-Rentería C, Ferreira-Hermosillo A, Albarrán-Sanchez A, Sosa-Eroza E, Molina-Ayala M, et al. Are there really any predictive factors for a successful weight loss after bariatric surgery? BMC Endocr Disord. 2020;20(1):20. https://doi.org/10.1186/s12902-020-0499-4.

28. Livhits M, Mercado C, Yermilov I, Parikh JA, Dutson E, Mehran A, et al. Preoperative predictors of weight loss following bariatric surgery: systematic review. Obes Surg. 2012;22(1):70-89. https://doi.org/10.1007/s11695-011-0472-4.

29. Baig SJ, Priya P, Mahawar KK, Shah S. Weight Regain After Bariatric Surgery-A Multicentre Study of 9617 Patients from Indian Bariatric Surgery Outcome Reporting Group. Obes Surg. 2019;29(5):1583-92. https://doi.org/10.1007/ s11695-019-03734-6.

30. Voorwinde V, Steenhuis IHM, Janssen IMC, Monpellier VM, van Stralen MM. Definitions of Long-Term Weight Regain and Their Associations with Clinical Outcomes. Obes Surg. 2020;30(2):527-36. https://doi.org/10.1007/s11695-019-04210-x.

31. Courcoulas AP, King WC, Belle SH, Berk P, Flum DR, Garcia L, et al. Seven-Year Weight Trajectories and Health Outcomes in the Longitudinal Assessment of Bariatric Surgery (LABS) Study. JAMA Surg. 2018;153(5):427-34. https://doi.org/10.1001/jamasurg.2017. 5025.

32. Monaco-Ferreira DV, Leandro-Merhi VA. Weight Regain 10 Years After Roux-en-Y Gastric Bypass. Obes Surg. 2017;27(5):1137-44. https://doi.org/10.1007/s11695-016-2426-3.

33. Shantavasinkul PC, Omotosho P, Corsino L, Portenier D, Torquati A. Predictors of weight regain in patients who underwent Roux-en-Y gastric bypass surgery. Surg Obes Relat Dis. 2016;12(9):1640-5. https://doi.org/10.1016/j.soard.2016.08.028.

34. Cooper TC, Simmons EB, Webb K, Burns JL, Kushner RF. Trends in Weight Regain Following Roux-en-Y Gastric Bypass (RYGB) Bariatric Surgery. Obes Surg. 2015;25(8):1474-81. https://doi.org/10.1007/s11695-014-1560-z.

35. Tsouristakis AI, Febres G, McMahon DJ, Tchang B, Conwell IM, Tsang AJ, et al. Long-Term Modulation of Appetitive Hormones and Sweet Cravings After Adjustable Gastric Banding and Rouxen-Y Gastric Bypass. Obes Surg. 2019;29(11):3698-705. https:// doi.org/10.1007/s11695-019-04111-z.

36. Varma S, Clark JM, Schweitzer M, Magnuson T, Brown TT, Lee CJ. Weight regain in patients with symptoms of post-bariatric surgery hypoglycemia. Surg Obes Relat Dis. 2017;13(10):172834. https://doi.org/10.1016/j.soard.2017.06.004.

37. Rusch MD, Andris D. Maladaptive eating patterns after weightloss surgery. Nutr Clin Pract. 2007;22(1):41-9. https://doi.org/ 10.1177/011542650702200141.

38. King WC, Hsu JY, Belle SH, Courcoulas AP, Eid GM, Flum DR, et al. Pre- to postoperative changes in physical activity: report from the longitudinal assessment of bariatric surgery-2 (LABS2). Surg Obes Relat Dis. 2012;8(5):522-32. https://doi.org/10. 1016/j.soard.2011.07.018.

39. Kalarchian MA, King WC, Devlin MJ, Marcus MD, Garcia L, Chen JY, et al. Psychiatric Disorders and Weight Change in a Prospective Study of Bariatric Surgery Patients: A 3-Year FollowUp. Psychosom Med. 2016;78(3):373-81. https://doi.org/10. 1097/psy.0000000000000277.

40. O'Brien PE, Hindle A, Brennan L, Skinner S, Burton P, Smith A, et al. Long-Term Outcomes After Bariatric Surgery: a Systematic Review and Meta-analysis of Weight Loss at 10 or More Years for All Bariatric Procedures and a Single-Centre Review of 20-Year Outcomes After Adjustable Gastric Banding. Obes Surg. 2019;29(1):3-14. https://doi.org/10.1007/s11695-018-3525-0.

41. Berger S, Meyre P, Blum S, Aeschbacher S, Ruegg M, Briel $\mathrm{M}$, et al. Bariatric surgery among patients with heart failure: a systematic review and meta-analysis. Open Heart. 2018;5(2): e000910. https://doi.org/10.1136/openhrt-2018-000910.

42. Carlin AM, Zeni TM, English WJ, Hawasli AA, Genaw JA, Krause KR, et al. The comparative effectiveness of sleeve gastrectomy, gastric bypass, and adjustable gastric banding procedures for the treatment of morbid obesity. Ann Surg. 2013;257(5):7917. https://doi.org/10.1097/SLA.0b013e3182879ded.

43. Maciejewski ML, Arterburn DE, Van Scoyoc L, Smith VA, Yancy WS Jr, Weidenbacher HJ, et al. Bariatric Surgery and Long-term Durability of Weight Loss. JAMA Surg. 2016;151(11):1046-55. https://doi.org/10.1001/jamasurg.2016.2317.

44. Arterburn DE, Telem DA, Kushner RF, Courcoulas AP. Benefits and Risks of Bariatric Surgery in Adults: A Review. JAMA. 2020;324(9):879-87. https://doi.org/10.1001/jama.2020.12567.

45. Lim R, Beekley A, Johnson DC, Davis KA. Early and late complications of bariatric operation. Trauma Surg Acute Care Open. 2018;3(1): e000219. https://doi.org/10.1136/tsaco-2018-000219.

46. Courcoulas A, Coley RY, Clark JM, McBride CL, Cirelli E, McTigue K, et al. Interventions and Operations 5 Years After Bariatric Surgery in a Cohort From the US National PatientCentered Clinical Research Network Bariatric Study. JAMA Surg. 2020;155(3):194-204. https://doi.org/10.1001/jamasurg. 2019.5470.

47. Lewis KH, Arterburn DE, Callaway K, Zhang F, Argetsinger S, Wallace J, et al. Risk of Operative and Nonoperative Interventions Up to 4 Years After Roux-en-Y Gastric Bypass vs Vertical Sleeve Gastrectomy in a Nationwide US Commercial Insurance Claims Database. JAMA Netw Open. 2019;2(12): e1917603. https://doi.org/10.1001/jamanetworkopen.2019.17603.

48. Mehaffey JH, LaPar DJ, Clement KC, Turrentine FE, Miller MS, Hallowell PT, et al. 10-Year Outcomes After Roux-en-Y Gastric Bypass. Ann Surg. 2016;264(1):121-6. https://doi.org/10.1097/ sla.0000000000001544.

49. Obeid NR, Malick W, Concors SJ, Fielding GA, Kurian MS, Ren-Fielding CJ. Long-term outcomes after Roux-en-Y gastric bypass: 10- to 13-year data. Surg Obes Relat Dis. 2016;12(1):1120. https://doi.org/10.1016/j.soard.2015.04.011.

50. Mehta A, Marso SP, Neeland IJ. Liraglutide for weight management: a critical review of the evidence. Obes Sci Pract. 2017;3(1):3-14. https://doi.org/10.1002/osp4.84.

51. O'Neil PM, Birkenfeld AL, McGowan B, Mosenzon O, Pedersen SD, Wharton S, et al. Efficacy and safety of semaglutide compared with liraglutide and placebo for weight loss in patients with obesity: a randomised, double-blind, placebo and active controlled, dose-ranging, phase 2 trial. Lancet. 2018;392(10148):637-49. https://doi.org/10.1016/s0140-6736(18)31773-2.

52. Son JW, Kim S. Comprehensive Review of Current and Upcoming Anti-Obesity Drugs. Diabetes Metab J. 2020;44(6):802-18. https://doi.org/10.4093/dmj.2020.0258. 
53. Rubino D, Abrahamsson N, Davies M, Hesse D, Greenway FL, Jensen C, et al. Effect of Continued Weekly Subcutaneous Semaglutide vs Placebo on Weight Loss Maintenance in Adults With Overweight or Obesity: The STEP 4 Randomized Clinical Trial. JAMA. 2021;325(14):1414-25. https://doi.org/10.1001/jama.2021.3224.

54. Durrer Schutz D, Busetto L, Dicker D, Farpour-Lambert N, Pryke R, Toplak H, et al. European Practical and Patient-Centred Guidelines for Adult Obesity Management in Primary Care. Obes Facts. 2019;12(1):40-66. https://doi.org/10.1159/000496183.

55. Di Lorenzo N, Antoniou SA, Batterham RL, Busetto L, Godoroja D, Iossa A, et al. Clinical practice guidelines of the European Association for Endoscopic Surgery (EAES) on bariatric surgery: update 2020 endorsed by IFSO-EC. EASO and ESPCOP Surg Endosc. 2020;34(6):2332-58. https://doi.org/10.1007/ s00464-020-07555-y.

56. Pelchat ML. Food addiction in humans. J Nutr. 2009;139(3):620 2. https://doi.org/10.3945/jn.108.097816.

57. van de Giessen E, Celik F, Schweitzer DH, van den Brink W, Booij J. Dopamine D2/3 receptor availability and amphetamineinduced dopamine release in obesity. J Psychopharmacol. 2014;28(9):866-73. https://doi.org/10.1177/0269881114531664.

58. Small DM, Jones-Gotman M, Dagher A. Feeding-induced dopamine release in dorsal striatum correlates with meal pleasantness ratings in healthy human volunteers. Neuroimage. 2003;19(4):1709-15. https://doi.org/10.1016/s1053-8119(03) 00253-2.

59. Drevets WC, Gautier C, Price JC, Kupfer DJ, Kinahan PE, Grace AA, et al. Amphetamine-induced dopamine release in human ventral striatum correlates with euphoria. Biol Psychiatry. 2001;49(2):81-96. https://doi.org/10.1016/s0006-3223(00) 01038-6.

60. Volkow ND, Wang GJ, Fowler JS, Logan J, Gatley SJ, Hitzemann $\mathrm{R}$, et al. Decreased striatal dopaminergic responsiveness in detoxified cocaine-dependent subjects. Nature. 1997;386(6627):830-3. https://doi.org/10.1038/386830a0.

61. Volkow ND, Chang L, Wang GJ, Fowler JS, Ding YS, Sedler M, et al. Low level of brain dopamine D2 receptors in methamphetamine abusers: association with metabolism in the orbitofrontal cortex. Am J Psychiatry. 2001;158(12):2015-21. https://doi.org/ 10.1176/appi.ajp.158.12.2015.

62. Kessler RM, Zald DH, Ansari MS, Li R, Cowan RL. Changes in dopamine release and dopamine D2/3 receptor levels with the development of mild obesity. Synapse. 2014;68(7):317-20. https://doi.org/10.1002/syn.21738.

63. Geiger BM, Haburcak M, Avena NM, Moyer MC, Hoebel BG, Pothos EN. Deficits of mesolimbic dopamine neurotransmission in rat dietary obesity. Neuroscience. 2009;159(4):1193-9. https:// doi.org/10.1016/j.neuroscience.2009.02.007.

64. Hardman CA, Herbert VM, Brunstrom JM, Munafò MR, Rogers PJ. Dopamine and food reward: effects of acute tyrosine/phenylalanine depletion on appetite. Physiol Behav. 2012;105(5):1202-7. https://doi.org/10.1016/j.physbeh.2011.12.022.

65. Tellez LA, Medina S, Han W, Ferreira JG, Licona-Limón P, Ren $\mathrm{X}$, et al. A gut lipid messenger links excess dietary fat to dopamine deficiency. Science. 2013;341(6147):800-2. https://doi.org/ 10.1126/science. 1239275.

66. Brauer LH, De Wit H. High dose pimozide does not block amphetamine-induced euphoria in normal volunteers. Pharmacol Biochem Behav. 1997;56(2):265-72. https://doi.org/10.1016/ s0091-3057(96)00240-7.

67. Leyton M, Casey KF, Delaney JS, Kolivakis T, Benkelfat C. Cocaine craving, euphoria, and self-administration: a preliminary study of the effect of catecholamine precursor depletion. Behav Neurosci. 2005;119(6):1619-27. https://doi.org/10.1037/07357044.119.6.1619.
68. Stice E, Yokum S. Neural vulnerability factors that increase risk for future weight gain. Psychol Bull. 2016;142(5):447-71. https://doi.org/10.1037/bul0000044.

69. Devoto F, Zapparoli L, Bonandrini R, Berlingeri M, Ferrulli A, Luzi L, et al. Hungry brains: A meta-analytical review of brain activation imaging studies on food perception and appetite in obese individuals. Neurosci Biobehav Rev. 2018;94:271-85. https://doi.org/10.1016/j.neubiorev.2018.07.017.

70. Morales I, Berridge KC. "Liking" and "wanting" in eating and food reward: Brain mechanisms and clinical implications. Physiol Behav. 2020;227: 113152. https://doi.org/10.1016/j.physbeh. 2020.113152.

71. Dobbs LK, Kaplan AR, Bock R, Phamluong K, Shin JH, Bocarsly ME, et al. D1 receptor hypersensitivity in mice with low striatal D2 receptors facilitates select cocaine behaviors. Neuropsychopharmacology. 2019;44(4):805-16. https://doi.org/ 10.1038/s41386-018-0286-3.

72. Steele KE, Prokopowicz GP, Schweitzer MA, Magunsuon TH, Lidor AO, Kuwabawa H, et al. Alterations of central dopamine receptors before and after gastric bypass surgery. Obes Surg. 2010;20(3):369-74. https://doi.org/10.1007/s11695-009-0015-4.

73. Karlsson HK, Tuominen L, Helin S, Salminen P, Nuutila P, Nummenmaa L. Preoperative brain $\mu$-opioid receptor availability predicts weight development following bariatric surgery in women. JCI Insight. 2021;6(10). https://doi.org/10.1172/jci. insight. 147820.

74. Robbins TW, Ersche KD, Everitt BJ. Drug addiction and the memory systems of the brain. Ann N Y Acad Sci. 2008;1141:121. https://doi.org/10.1196/annals.1441.020.

75. Schultz W, Dayan P, Montague PR. A neural substrate of prediction and reward. Science. 1997;275(5306):1593-9. https://doi. org/10.1126/science.275.5306.1593.

76. Hamid AA, Pettibone JR, Mabrouk OS, Hetrick VL, Schmidt R, Vander Weele CM, et al. Mesolimbic dopamine signals the value of work. Nat Neurosci. 2016;19(1):117-26. https://doi.org/10. 1038/nn.4173.

77. Han P, Roitzsch C, Horstmann A, Pössel M, Hummel T. Increased Brain Reward Responsivity to Food-Related Odors in Obesity. Obesity (Silver Spring). 2021;29(7):1138-45. https:// doi.org/10.1002/oby.23170.

78. Martin LE, Holsen LM, Chambers RJ, Bruce AS, Brooks WM, Zarcone JR, et al. Neural mechanisms associated with food motivation in obese and healthy weight adults. Obesity (Silver Spring). 2010;18(2):254-60. https://doi.org/10.1038/oby.2009. 220.

79. Stoeckel LE, Weller RE, Cook EW 3rd, Twieg DB, Knowlton $\mathrm{RC}$, Cox JE. Widespread reward-system activation in obese women in response to pictures of high-calorie foods. Neuroimage. 2008;41(2):636-47. https://doi.org/10.1016/j.neuroimage. 2008.02.031.

80. Rothemund Y, Preuschhof C, Bohner G, Bauknecht HC, Klingebiel $\mathrm{R}$, Flor H, et al. Differential activation of the dorsal striatum by high-calorie visual food stimuli in obese individuals. Neuroimage. 2007;37(2):410-21. https://doi.org/10.1016/j.neuroimage.2007.05. 008.

81. Hickey C, Chelazzi L, Theeuwes J. Reward changes salience in human vision via the anterior cingulate. J Neurosci. 2010;30(33):11096-103. https://doi.org/10.1523/jneurosci.102610.2010.

82. Ito R, Everitt BJ, Robbins TW. The hippocampus and appetitive Pavlovian conditioning: effects of excitotoxic hippocampal lesions on conditioned locomotor activity and autoshaping. Hippocampus. 2005;15(6):713-21. https://doi.org/10.1002/hipo.20094.

83. Rypma B, Fischer H, Rieckmann A, Hubbard NA, Nyberg L, Bäckman L. Dopamine D1 Binding Potential Predicts Fusiform BOLD Activity during Face-Recognition Performance. J 
Neurosci. 2015;35(44):14702-7. https://doi.org/10.1523/ jneurosci.1298-15.2015.

84. Ostlund SB, Balleine BW. Orbitofrontal cortex mediates outcome encoding in Pavlovian but not instrumental conditioning. J Neurosci. 2007;27(18):4819-25. https://doi.org/10.1523/jneurosci. 5443-06.2007.

85. Bach P, Grosshans M, Koopmann A, Pfeifer AM, Vollstädt-Klein $\mathrm{S}$, Otto M, et al. Predictors of weight loss in participants with obesity following bariatric surgery - A prospective longitudinal fMRI study. Appetite. 2021;163: 105237. https://doi.org/10. 1016/j.appet.2021.105237.

86. Ten Kulve JS, Veltman DJ, van Bloemendaal L, Barkhof F, Drent ML, Diamant M, et al. Liraglutide Reduces CNS Activation in Response to Visual Food Cues Only After Short-term Treatment in Patients With Type 2 Diabetes. Diabetes Care. 2016;39(2):214-21. https://doi.org/10.2337/dc15-0772.

87. McClure SM, Laibson DI, Loewenstein G, Cohen JD. Separate neural systems value immediate and delayed monetary rewards. Science. 2004;306(5695):503-7. https://doi.org/10.1126/science. 1100907.

88. Hare TA, Camerer CF, Rangel A. Self-control in decision-making involves modulation of the vmPFC valuation system. Science. 2009;324(5927):646-8. https://doi.org/10.1126/science.1168450.

89. Kahathuduwa CN, Davis T, O'Boyle M, Boyd LA, Chin SH, Paniukov D et al. Effects of 3-week total meal replacement vs. typical food-based diet on human brain functional magnetic resonance imaging food-cue reactivity and functional connectivity in people with obesity. Appetite. 2018;120:431-41. https://doi.org/ 10.1016/j.appet.2017.09.025.

90. Sotak BN, Hnasko TS, Robinson S, Kremer EJ, Palmiter RD. Dysregulation of dopamine signaling in the dorsal striatum inhibits feeding. Brain Res. 2005;1061(2):88-96. https://doi.org/10. 1016/j.brainres.2005.08.053.

91. Balleine BW, Dickinson A. The effect of lesions of the insular cortex on instrumental conditioning: evidence for a role in incentive memory. J Neurosci. 2000;20(23):8954-64. https://doi.org/ 10.1523/jneurosci.20-23-08954.2000.

92. Bickel WK, George Wilson A, Franck CT, Terry Mueller E, Jarmolowicz DP, Koffarnus MN, et al. Using crowdsourcing to compare temporal, social temporal, and probability discounting among obese and non-obese individuals. Appetite. 2014;75:829. https://doi.org/10.1016/j.appet.2013.12.018.

93. Jarmolowicz DP, Cherry JB, Reed DD, Bruce JM, Crespi JM, Lusk JL, et al. Robust relation between temporal discounting rates and body mass. Appetite. 2014;78:63-7. https://doi.org/10. 1016/j.appet.2014.02.013.

94. Nederkoorn C, Smulders FT, Havermans RC, Roefs A, Jansen A. Impulsivity in obese women. Appetite. 2006;47(2):253-6. https://doi.org/10.1016/j.appet.2006.05.008.

95. Buono FD, Whiting SW, Sprong ME. Comparison of temporal discounting among obese college students and obese adults. Behavior Analysis: Research and Practice. 2015;15(2):139-47. https://doi.org/10.1037/bar0000015.

96. Volkow ND, Wang GJ, Telang F, Fowler JS, Thanos PK, Logan $\mathrm{J}$, et al. Low dopamine striatal D2 receptors are associated with prefrontal metabolism in obese subjects: possible contributing factors. Neuroimage. 2008;42(4):1537-43. https://doi.org/10. 1016/j.neuroimage.2008.06.002.

97. Weygandt M, Mai K, Dommes E, Leupelt V, Hackmack K, Kahnt $\mathrm{T}$, et al. The role of neural impulse control mechanisms for dietary success in obesity. Neuroimage. 2013;83:669-78. https:// doi.org/10.1016/j.neuroimage.2013.07.028.

98. Logothetis NK, Pauls J, Augath M, Trinath T, Oeltermann A. Neurophysiological investigation of the basis of the fMRI signal. Nature. 2001;412(6843):150-7. https://doi.org/10.1038/35084005.
99. Hu Y, Ji G, Li G, Manza P, Zhang W, Wang J, et al. Brain Connectivity, and Hormonal and Behavioral Correlates of Sustained Weight Loss in Obese Patients after Laparoscopic Sleeve Gastrectomy. Cereb Cortex. 2021;31(2):1284-95. https://doi.org/10. 1093/cercor/bhaa294.

100. Li P, Shan H, Nie B, Liu H, Dong G, Guo Y, et al. Sleeve Gastrectomy Rescuing the Altered Functional Connectivity of Lateral but Not Medial Hypothalamus in Subjects with Obesity. Obes Surg. 2019;29(7):2191-9. https://doi.org/10.1007/ s11695-019-03822-7.

101. Paolini BM, Laurienti PJ, Simpson SL, Burdette JH, Lyday RG, Rejeski WJ. Global integration of the hot-state brain network of appetite predicts short term weight loss in older adult. Front Aging Neurosci. 2015;7:70. https://doi.org/10.3389/ fnagi.2015.00070.

102. Friston KJ, Buechel C, Fink GR, Morris J, Rolls E, Dolan RJ. Psychophysiological and modulatory interactions in neuroimaging. Neuroimage. 1997;6(3):218-29. https://doi.org/10.1006/ nimg.1997.0291.

103. Weller RE, Cook EW 3rd, Avsar KB, Cox JE. Obese women show greater delay discounting than healthy-weight women. Appetite. 2008;51(3):563-9. https://doi.org/10.1016/j.appet. 2008.04.010.

104. Kishinevsky FI, Cox JE, Murdaugh DL, Stoeckel LE, Cook EW 3rd, Weller RE. fMRI reactivity on a delay discounting task predicts weight gain in obese women. Appetite. 2012;58(2):582-92. https://doi.org/10.1016/j.appet.2011.11. 029.

105. Miranda-Olivos R, Steward T, Martínez-Zalacaín I, Mestre-Bach G, Juaneda-Seguí A, Jiménez-Murcia S, et al. The neural correlates of delay discounting in obesity and binge eating disorder. J Behav Addict. 2021. https://doi.org/10.1556/2006.2021.00023.

106. Weygandt M, Mai K, Dommes E, Ritter K, Leupelt V, Spranger $\mathrm{J}$, et al. Impulse control in the dorsolateral prefrontal cortex counteracts post-diet weight regain in obesity. Neuroimage. 2015;109:318-27. https://doi.org/10.1016/j.neuroimage.2014. 12.073 .

107. Kable JW, Glimcher PW. The neural correlates of subjective value during intertemporal choice. Nat Neurosci. 2007;10(12):1625-33. https://doi.org/10.1038/nn2007.

108. Steward T, Picó-Pérez M, Mestre-Bach G, Martínez-Zalacaín I, Suñol M, Jiménez-Murcia S, et al. A multimodal MRI study of the neural mechanisms of emotion regulation impairment in women with obesity. Transl Psychiatry. 2019;9(1):194. https:// doi.org/10.1038/s41398-019-0533-3.

109. Fox MD, Snyder AZ, Vincent JL, Corbetta M, Van Essen DC, Raichle ME. The human brain is intrinsically organized into dynamic, anticorrelated functional networks. Proc Natl Acad Sci U S A. 2005;102(27):9673-8. https://doi.org/10.1073/pnas. 0504136102.

110. Fox MD, Snyder AZ, Zacks JM, Raichle ME. Coherent spontaneous activity accounts for trial-to-trial variability in human evoked brain responses. Nat Neurosci. 2006;9(1):23-5. https://doi.org/ $10.1038 / \mathrm{nn} 1616$.

111. Li P, Shan H, Liang S, Nie B, Liu H, Duan S, et al. Sleeve Gastrectomy Recovering Disordered Brain Function in Subjects with Obesity: a Longitudinal fMRI Study. Obes Surg. 2018;28(8):2421-8. https://doi.org/10.1007/s11695-018-3178-Z.

112. Duan S, Ji G, Li G, Hu Y, Zhang W, Wang J, et al. Bariatric surgery induces alterations in effective connectivity between the orbitofrontal cortex and limbic regions in obese patients. SCIENCE CHINA Inf Sci. 2020;63(7): 170104. https://doi.org/10. 1007/s11432-019-2817-x.

113. Zhang Y, Ji G, Li G, Hu Y, Liu L, Jin Q, et al. Ghrelin reductions following bariatric surgery were associated with decreased 
resting state activity in the hippocampus. Int J Obes (Lond). 2019;43(4):842-51. https://doi.org/10.1038/s41366-018-0126-x.

114. Biswal BB, Kannurpatti SS, Rypma B. Hemodynamic scaling of fMRI-BOLD signal: validation of low-frequency spectral amplitude as a scalability factor. Magn Reson Imaging. 2007;25(10):1358-69. https://doi.org/10.1016/j.mri.2007.03.022.

115. Zang YF, He Y, Zhu CZ, Cao QJ, Sui MQ, Liang M, et al. Altered baseline brain activity in children with ADHD revealed by resting-state functional MRI. Brain Dev. 2007;29(2):83-91. https://doi.org/10.1016/j.braindev.2006.07.002.

116. Zou QH, Zhu CZ, Yang Y, Zuo XN, Long XY, Cao QJ, et al. An improved approach to detection of amplitude of low-frequency fluctuation (ALFF) for resting-state fMRI: fractional ALFF. J Neurosci Methods. 2008;172(1):137-41. https://doi.org/10. 1016/j.jneumeth.2008.04.012.

117. Lv H, Wang Z, Tong E, Williams LM, Zaharchuk G, Zeineh M, et al. Resting-State Functional MRI: Everything That Nonexperts Have Always Wanted to Know. AJNR Am J Neuroradiol. 2018;39(8):1390-9. https://doi.org/10.3174/ajnr.A5527.

118. Li G, Ji G, Hu Y, Xu M, Jin Q, Liu L, et al. Bariatric surgery in obese patients reduced resting connectivity of brain regions involved with self-referential processing. Hum Brain Mapp. 2018;39(12):4755-65. https://doi.org/10.1002/hbm.24320.

119. Tomasi D, Volkow ND. Functional connectivity density mapping. Proc Natl Acad Sci U S A. 2010;107(21):9885-90. https:// doi.org/10.1073/pnas.1001414107.

120. Zhuo C, Zhu J, Qin W, Qu H, Ma X, Tian H, et al. Functional connectivity density alterations in schizophrenia. Front Behav Neurosci. 2014;8:404. https://doi.org/10.3389/fnbeh.2014.00404.

121. Lan CC, Tsai SJ, Huang CC, Wang YH, Chen TR, Yeh HL, et al. Functional Connectivity Density Mapping of Depressive Symptoms and Loneliness in Non-Demented Elderly Male. Front Aging Neurosci. 2015;7:251. https://doi.org/10.3389/fnagi.2015. 00251.

122. Calhoun VD, Adali T, Pearlson GD, Pekar JJ. A method for making group inferences from functional MRI data using independent component analysis. Hum Brain Mapp. 2001;14(3):140-51. https://doi.org/10.1002/hbm.1048.

123. Saindane AM, Drane DL, Singh A, Wu J, Qiu D. Neuroimaging correlates of cognitive changes after bariatric surgery. Surg Obes Relat Dis. 2020;16(1):119-27. https://doi.org/10.1016/j.soard. 2019.09.076.

124. McFadden KL, Cornier MA, Melanson EL, Bechtell JL, Tregellas JR. Effects of exercise on resting-state default mode and salience network activity in overweight/obese adults. NeuroReport. 2013;24(15):86671. https://doi.org/10.1097/wnr.0000000000000013.

125. Contreras-Rodríguez O, Martín-Pérez C, Vilar-López R, VerdejoGarcia A. Ventral and Dorsal Striatum Networks in Obesity: Link to Food Craving and Weight Gain. Biol Psychiatry. 2017;81(9):789_ 96. https://doi.org/10.1016/j.biopsych.2015.11.020.

126. Cerit H, Davidson P, Hye T, Moondra P, Haimovici F, Sogg S, et al. Resting-State Brain Connectivity Predicts Weight Loss and Cognitive Control of Eating Behavior After Vertical Sleeve Gastrectomy. Obesity (Silver Spring). 2019;27(11):1846-55. https:// doi.org/10.1002/oby.22607.

127. Schmidt L, Medawar E, Aron-Wisnewsky J, Genser L, Poitou $\mathrm{C}$, Clément $\mathrm{K}$ et al. Resting-state connectivity within the brain's reward system predicts weight loss and correlates with leptin. Brain Commun. 2021;3(1):fcab005. https://doi.org/10.1093/braincomms/ fcab005

128. Dong TS, Gupta A, Jacobs JP, Lagishetty V, Gallagher E, Bhatt RR et al. Improvement in Uncontrolled Eating Behavior after Laparoscopic Sleeve Gastrectomy Is Associated with Alterations in the Brain-Gut-Microbiome Axis in Obese Women. Nutrients. 2020;12(10). https://doi.org/10.3390/nu12102924.
129. Levakov G, Kaplan A, Yaskolka Meir A, Rinott E, Tsaban G, Zelicha $\mathrm{H}$, et al. Neural correlates of future weight loss reveal a possible role for brain-gastric interactions. Neuroimage. 2021;224: 117403. https://doi.org/10.1016/j.neuroimage.2020.117403.

130. Zhang W, Ji G, Manza P, Li G, Hu Y, Wang J, et al. ConnectomeBased Prediction of Optimal Weight Loss Six Months After Bariatric Surgery. Cereb Cortex. 2021;31(5):2561-73. https://doi.org/ 10.1093/cercor/bhaa374.

131. Olivo G, Zhou W, Sundbom M, Zhukovsky C, Hogenkamp P, Nikontovic L, et al. Resting-state brain connectivity changes in obese women after Roux-en-Y gastric bypass surgery: A longitudinal study. Sci Rep. 2017;7(1):6616. https://doi.org/ 10.1038/s41598-017-06663-5.

132. Mokhtari F, Rejeski WJ, Zhu Y, Wu G, Simpson SL, Burdette JH, et al. Dynamic fMRI networks predict success in a behavioral weight loss program among older adults. Neuroimage. 2018;173:421-33. https://doi.org/10.1016/j.neuroimage.2018.02.025.

133. Rubinov M, Sporns O. Complex network measures of brain connectivity: uses and interpretations. Neuroimage. 2010;52(3):1059-69. https://doi.org/10.1016/j.neuroimage. 2009.10.003.

134. Latora V, Marchiori M. Efficient behavior of small-world networks. Phys Rev Lett. 2001;87(19): 198701. https://doi.org/10. 1103/PhysRevLett.87.198701.

135. Achard S, Bullmore E. Efficiency and cost of economical brain functional networks. PLoS Comput Biol. 2007;3(2): e17. https://doi.org/10.1371/journal.pcbi.0030017.

136. Michaud A, Dadar M, Pelletier M, Zeighami Y, Garcia-Garcia I, Iceta $S$, et al. Neuroanatomical changes in white and grey matter after sleeve gastrectomy. Neuroimage. 2020;213: 116696 https://doi.org/10.1016/j.neuroimage.2020.116696.

137. Rullmann M, Preusser S, Poppitz S, Heba S, Hoyer J, Schütz T, et al. Gastric-bypass surgery induced widespread neural plasticity of the obese human brain. Neuroimage. 2018;172:85363. https://doi.org/10.1016/j.neuroimage.2017.10.062.

138. Best JR, Chiu BK, Hall PA, Liu-Ambrose T. Larger Lateral Prefrontal Cortex Volume Predicts Better Exercise Adherence Among Older Women: Evidence From Two Exercise Training Studies. J Gerontol A Biol Sci Med Sci. 2017;72(6):804-10. https://doi.org/10.1093/gerona/glx043.

139. Gujral S, McAuley E, Oberlin LE, Kramer AF, Erickson KI. Role of Brain Structure in Predicting Adherence to a Physical Activity Regimen. Psychosom Med. 2018;80(1):69-77. https:// doi.org/10.1097/psy.0000000000000526.

140. Honea RA, Szabo-Reed AN, Lepping RJ, Perea R, Breslin F, Martin LE, et al. Voxel-based morphometry reveals brain gray matter volume changes in successful dieters. Obesity (Silver Spring). 2016;24(9):1842-8. https://doi.org/10.1002/oby. 21551.

141. Mokhtari F, Paolini BM, Burdette JH, Marsh AP, Rejeski WJ, Laurienti PJ. Baseline gray- and white-matter volume predict successful weight loss in the elderly. Obesity (Silver Spring). 2016;24(12):2475-80. https://doi.org/10.1002/oby.21652.

142. Tuulari JJ, Karlsson HK, Antikainen O, Hirvonen J, Pham T, Salminen P, et al. Bariatric Surgery Induces White and Grey Matter Density Recovery in the Morbidly Obese: A Voxel-Based Morphometric Study. Hum Brain Mapp. 2016;37(11):3745-56. https://doi.org/10.1002/hbm.23272.

143. Mueller K, Möller HE, Horstmann A, Busse F, Lepsien J, Blüher $\mathrm{M}$, et al. Physical exercise in overweight to obese individuals induces metabolic- and neurotrophic-related structural brain plasticity. Front Hum Neurosci. 2015;9:372. https://doi.org/10.3389/ fnhum.2015.00372.

144. Ashburner J, Friston KJ. Unified segmentation. Neuroimage. 2005;26(3):839-51. https://doi.org/10.1016/j.neuroimage. 2005. 02.018 . 
145. Desikan RS, Ségonne F, Fischl B, Quinn BT, Dickerson BC, Blacker D, et al. An automated labeling system for subdividing the human cerebral cortex on MRI scans into gyral based regions of interest. Neuroimage. 2006;31(3):968-80. https://doi.org/10. 1016/j.neuroimage.2006.01.021.

146. Fischl B, Salat DH, Busa E, Albert M, Dieterich M, Haselgrove C, et al. Whole brain segmentation: automated labeling of neuroanatomical structures in the human brain. Neuron. 2002;33(3):34155. https://doi.org/10.1016/s0896-6273(02)00569-x.

147. Guo C, Ferreira D, Fink K, Westman E, Granberg T. Repeatability and reproducibility of FreeSurfer, FSL-SIENAX and SPM brain volumetric measurements and the effect of lesion filling in multiple sclerosis. Eur Radiol. 2019;29(3):1355-64. https://doi. org/10.1007/s00330-018-5710-x.

148. Liu L, Ji G, Li G, Hu Y, Jin Q, Hu C, et al. Structural changes in brain regions involved in executive-control and self-referential processing after sleeve gastrectomy in obese patients. Brain Imaging Behav. 2019;13(3):830-40. https://doi.org/10.1007/ s11682-018-9904-2.

149. Mori S. Introduction to Diffusion Tensor Imaging. Amsterdam: Elsevier Science B.V; 2007.

150. Soares JM, Marques P, Alves V, Sousa N. A hitchhiker's guide to diffusion tensor imaging. Front Neurosci. 2013;7:31. https:// doi.org/10.3389/fnins.2013.00031.

151. Maier-Hein KH, Neher PF, Houde JC, Côté MA, Garyfallidis E, Zhong J, et al. The challenge of mapping the human connectome based on diffusion tractography. Nat Commun. 2017;8(1):1349. https://doi.org/10.1038/s41467-017-01285-x.

152. Jenkinson M, Beckmann CF, Behrens TE, Woolrich MW, Smith SM. FSL Neuroimage. 2012;62(2):782-90. https://doi.org/10. 1016/j.neuroimage.2011.09.015.

153. Cox RW. AFNI: what a long strange trip it's been. Neuroimage. 2012;62(2):743-7. https://doi.org/10.1016/j.neuroimage.2011. 08.056 .

154. Goebel R. BrainVoyager-past, present, future. Neuroimage. 2012;62(2):748-56. https://doi.org/10.1016/j.neuroimage.2012. 01.083 .

155. Han H, Glenn AL, Dawson KJ. Evaluating Alternative Correction Methods for Multiple Comparison in Functional Neuroimaging Research. Brain Sci. 2019;9(8). https://doi.org/10.3390/ brainsci9080198.

156. Brett M, Penny W, Kiebel S. Introduction to random field theory. Human brain function. 2003;2:867-79.

157. Nichols T, Hayasaka S. Controlling the familywise error rate in functional neuroimaging: a comparative review. Stat Methods Med Res. 2003;12(5):419-46. https://doi.org/10.1191/0962280203sm341ra.

158. Eklund A, Nichols TE, Knutsson H. Cluster failure: Why fMRI inferences for spatial extent have inflated false-positive rates. Proc Natl Acad Sci U S A. 2016;113(28):7900-5. https://doi. org/10.1073/pnas.1602413113.

159. Winkler AM, Ridgway GR, Webster MA, Smith SM, Nichols TE. Permutation inference for the general linear model. Neuroimage. 2014;92(100):381-97. https://doi.org/10.1016/j.neuroimage. 2014.01.060.

160. Fischl B. FreeSurfer Neuroimage. 2012;62(2):774-81. https:// doi.org/10.1016/j.neuroimage.2012.01.021.

161. Bernal-Rusiel JL, Greve DN, Reuter M, Fischl B, Sabuncu MR. Statistical analysis of longitudinal neuroimage data with Linear Mixed Effects models. Neuroimage. 2013;66:249-60. https://doi. org/10.1016/j.neuroimage.2012.10.065.

162. Verbeke G, Molenberghs G. Linear mixed models for longitudinal data. New York: Springer; 2000.

163. Maurer L, Mai K, Krude H, Haynes JD, Weygandt M, Spranger $\mathrm{J}$. Interaction of circulating GLP-1 and the response of the dorsolateral prefrontal cortex to food-cues predicts body weight development. Mol Metab. 2019;29:136-44. https://doi.org/10. 1016/j.molmet.2019.08.014.

164. Schölkopf B, Smola AJ, Bach F. Learning with kernels: support vector machines, regularization, optimization, and beyond. MIT press; 2002.

165. Wolfers T, Buitelaar JK, Beckmann CF, Franke B, Marquand AF. From estimating activation locality to predicting disorder: A review of pattern recognition for neuroimaging-based psychiatric diagnostics. Neurosci Biobehav Rev. 2015;57:328-49. https:// doi.org/10.1016/j.neubiorev.2015.08.001.

166. Noirhomme Q, Lesenfants D, Gomez F, Soddu A, Schrouff J, Garraux $\mathrm{G}$, et al. Biased binomial assessment of cross-validated estimation of classification accuracies illustrated in diagnosis predictions. Neuroimage Clin. 2014;4:687-94. https://doi.org/ 10.1016/j.nicl.2014.04.004.

167. Weygandt M, Hummel HM, Schregel K, Ritter K, Allefeld C, Dommes E, et al. MRI-based diagnostic biomarkers for early onset pediatric multiple sclerosis. Neuroimage Clin. 2015;7:4008. https://doi.org/10.1016/j.nicl.2014.06.015.

168. Jöreskog KG. A general method for estimating a linear structural equation system. ETS Research Bulletin Series. 1970;1970(2):i-41.

169. Szabo-Reed AN, Martin LE, Hu J, Yeh HW, Powell J, Lepping RJ, et al. Modeling interactions between brain function, diet adherence behaviors, and weight loss success. Obes Sci Pract. 2020;6(3):282-92. https://doi.org/10.1002/osp4.403.

170. Bollen KA, Kolenikov S, Bauldry S. Model-implied instrumental variable-generalized method of moments (MIIV-GMM) estimators for latent variable models. Psychometrika. 2014;79(1):20 50. https://doi.org/10.1007/s11336-013-9335-3.

171. Kock N, Hadaya P. Minimum sample size estimation in PLSSEM: The inverse square root and gamma-exponential methods. Inf Syst J. 2018;28(1):227-61. https://doi.org/10.1111/isj.12131.

172. Weygandt M, Hackmack K, Pfüller CF, Bellmann-Strobl J, Paul F, Zipp F, Haynes JD. MRI Pattern Recognition in Multiple Sclerosis Normal-Appearing Brain Areas. PLoS One. 2011;6:e21138.

173. Schur EA, Melhorn SJ, Scholz K, De Leon MRB, Elfers CT, Rowland MG, et al. Child neurobiology impacts success in family-based behavioral treatment for children with obesity. Int J Obes (Lond). 2020;44(10):2011-22. https://doi.org/10.1038/ s41366-020-0644-1.

174. Hermann P, Gál V, Kóbor I, Kirwan CB, Kovács P, Kitka T, et al. Efficacy of weight loss intervention can be predicted based on early alterations of fMRI food cue reactivity in the striatum. Neuroimage Clin. 2019;23: 101803. https://doi.org/10.1016/j. nicl.2019.101803.

175. Murdaugh DL, Cox JE, Cook EW 3rd, Weller RE. fMRI reactivity to high-calorie food pictures predicts short- and long-term outcome in a weight-loss program. Neuroimage. 2012;59(3):2709_ 21. https://doi.org/10.1016/j.neuroimage.2011.10.071.

176. Smith KR, Papantoni A, Veldhuizen MG, Kamath V, Harris C, Moran TH, et al. Taste-related reward is associated with weight loss following bariatric surgery. J Clin Invest. 2020;130(8):437081. https://doi.org/10.1172/jci137772.

177. Ochner CN, Stice E, Hutchins E, Afifi L, Geliebter A, Hirsch $\mathrm{J}$, et al. Relation between changes in neural responsivity and reductions in desire to eat high-calorie foods following gastric bypass surgery. Neuroscience. 2012;209:128-35. https://doi.org/ 10.1016/j.neuroscience.2012.02.030.

178. Ness A, Bruce J, Bruce A, Aupperle R, Lepping R, Martin L, et al. Pre-surgical cortical activation to food pictures is associated with weight loss following bariatric surgery. Surg Obes Relat Dis. 2014;10(6):1188-95. https://doi.org/10.1016/j.soard.2014. 06.005 .

179. Neseliler S, Hu W, Larcher K, Zacchia M, Dadar M, Scala SG, et al. Neurocognitive and Hormonal Correlates of Voluntary 
Weight Loss in Humans. Cell Metab. 2019;29(1):39-49.e4. https://doi.org/10.1016/j.cmet.2018.09.024.

180. Drummen M, Dorenbos E, Vreugdenhil ACE, Stratton G, Raben A, Westerterp-Plantenga MS et al. Associations of Brain Reactivity to Food Cues with Weight Loss, Protein Intake and Dietary Restraint during the PREVIEW Intervention. Nutrients. 2018;10(11). https://doi.org/10.3390/nu10111771.

181. Parsons N, Steward T, Clohesy R, Almgren H, Duehlmeyer L. A systematic review of resting-state functional connectivity in obesity: Refining current neurobiological frameworks and methodological considerations moving forward. Rev Endocr Metab Disord. 2021. https://doi.org/10.1007/s11154-021-09665-x.

182. Lin L, Chu H. Quantifying publication bias in meta-analysis. Biometrics. 2018;74(3):785-94. https://doi.org/10.1111/biom. 12817.

183. Dubois J, Adolphs R. Building a Science of Individual Differences from fMRI. Trends Cogn Sci. 2016;20(6):425-43. https:// doi.org/10.1016/j.tics.2016.03.014.

184. Kriegeskorte N, Simmons WK, Bellgowan PS, Baker CI. Circular analysis in systems neuroscience: the dangers of double dipping. Nat Neurosci. 2009;12(5):535-40. https://doi.org/10. 1038/nn.2303.

185. Vul E, Harris C, Winkielman P, Pashler H. Puzzlingly High Correlations in fMRI Studies of Emotion, Personality, and Social Cognition. Perspect Psychol Sci. 2009;4(3):274-90. https://doi. org/10.1111/j.1745-6924.2009.01125.x.

186. Shrout PE, Fleiss JL. Intraclass correlations: uses in assessing rater reliability. Psychol Bull. 1979;86(2):420-8. https://doi.org/ 10.1037//0033-2909.86.2.420.

187. Cicchetti DV. The precision of reliability and validity estimates re-visited: distinguishing between clinical and statistical significance of sample size requirements. J Clin Exp Neuropsychol. 2001;23(5):695-700. https://doi.org/10.1076/jcen.23.5.695.1249.

188. Bennett CM, Miller MB. How reliable are the results from functional magnetic resonance imaging? Ann N Y Acad Sci. 2010;1191:133-55. https://doi.org/10.1111/j.1749-6632.2010. 05446.x.

189. Elliott ML, Knodt AR, Ireland D, Morris ML, Poulton R, Ramrakha S, et al. What Is the Test-Retest Reliability of Common Task-Functional MRI Measures? New Empirical Evidence and a Meta-Analysis. Psychol Sci. 2020;31(7):792-806. https://doi.org/10.1177/0956797620916786.

190. Noble S, Scheinost D, Constable RT. A decade of test-retest reliability of functional connectivity: A systematic review and meta-analysis. Neuroimage. 2019;203: 116157. https://doi.org/ 10.1016/j.neuroimage.2019.116157.

191. Han X, Jovicich J, Salat D, van der Kouwe A, Quinn B, Czanner S, et al. Reliability of MRI-derived measurements of human cerebral cortical thickness: the effects of field strength, scanner upgrade and manufacturer. Neuroimage. 2006;32(1):180-94. https://doi.org/10. 1016/j.neuroimage.2006.02.051.

192. Heise DR. Separating reliability and stability in test-retest correlation. American sociological review. 1969:93-101.

193. Fröhner JH, Teckentrup V, Smolka MN, Kroemer NB. Addressing the reliability fallacy in fMRI: Similar group effects may arise from unreliable individual effects. Neuroimage. 2019;195:17489. https://doi.org/10.1016/j.neuroimage.2019.03.053.

194. Wang J, Ren Y, Hu X, Nguyen VT, Guo L, Han J, et al. Testretest reliability of functional connectivity networks during naturalistic fMRI paradigms. Hum Brain Mapp. 2017;38(4):2226-41. https://doi.org/10.1002/hbm.23517.

195. Hege MA, Stingl KT, Ketterer C, Häring HU, Heni M, Fritsche A, et al. Working memory-related brain activity is associated with outcome of lifestyle intervention. Obesity (Silver Spring). 2013;21(12):2488-94. https://doi.org/10.1002/oby.20442.

196. Holsen LM, Davidson P, Cerit H, Hye T, Moondra P, Haimovici $F$, et al. Neural predictors of 12-month weight loss outcomes following bariatric surgery. Int J Obes (Lond). 2018;42(4):785-93. https://doi.org/10.1038/ijo.2017.190.

197. Bruce JM, Hancock L, Bruce A, Lepping RJ, Martin L, Lundgren $\mathrm{JD}$, et al. Changes in brain activation to food pictures after adjustable gastric banding. Surg Obes Relat Dis. 2012;8(5):602-8. https://doi.org/10.1016/j.soard.2011.07.006.

198. Zoon HFA, de Bruijn SEM, Smeets PAM, de Graaf C, Janssen IMC, Schijns W, et al. Altered neural responsivity to food cues in relation to food preferences, but not appetite-related hormone concentrations after RYGB-surgery. Behav Brain Res. 2018;353:194202. https://doi.org/10.1016/j.bbr.2018.07.016.

199. Ten Kulve JS, Veltman DJ, van Bloemendaal L, Groot PF, Ruhé HG, Barkhof F, et al. Endogenous GLP1 and GLP1 analogue alter CNS responses to palatable food consumption. J Endocrinol. 2016;229(1):1-12. https://doi.org/10.1530/joe-15-0461.

Publisher's Note Springer Nature remains neutral with regard to jurisdictional claims in published maps and institutional affiliations. 